\title{
Synthesis and Basicity Studies of Quinolino[7,8-h]quinoline Derivatives
}

Gareth J. Rowlands, Rebecca J. Severinsen, Jenna K. Buchanan, Karl J. Shaffer, Heather T. Jameson, Nishani Thennakoon, Ivo Leito, Märt Lõkov, Agnes Kütt, Robert Vianello, Ines Despotović, Nena Radić, and Paul G. Plieger*

Cite This: J. Org. Chem. 2020, 85, 11297-11308

Read Online

ACCESS | Lلll Metrics \& More | 回 Article Recommendations ｜（s Supporting Information

ABSTRACT: Quinolino[7,8- $h]$ quinoline is a superbasic compound, with a $\mathrm{p} K_{\mathrm{aH}}$ in acetonitrile greater than that of 1,8-bis(dimethylaminonaphthalene) (DMAN), although its synthesis and the synthesis of its derivatives can be problematic. The use of halogen derivatives 4,9-dichloroquinolino[7,8$h]$ quinoline (16) and 4,9-dibromoquinolino[7,8-h]quinoline (17) as precursors has granted the formation of a range of substituted quinolinoquinolines. The basicity and other properties of quinolinoquinolines can be modified by the inclusion of suitable functionalities. The experimentally obtained $\mathrm{p} K_{\mathrm{aH}}$ values of quinolino[7,8- $\left.h\right]$ quinoline derivatives show that $N^{4}, N^{4}, N^{9}, N^{9}$-tetraethylquinolino[7,8-h] quinoline-4,9-diamine (26)

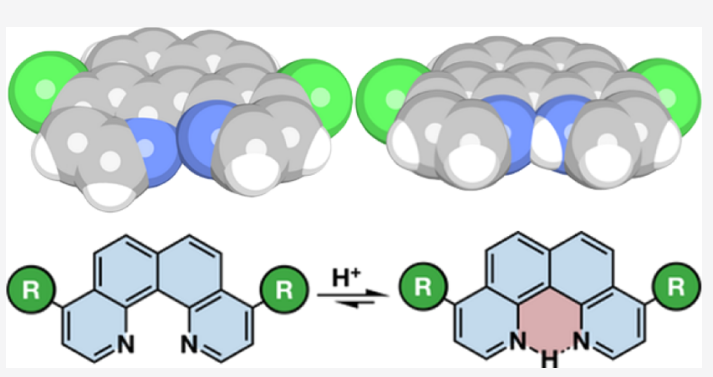
is more superbasic than quinolino[7,8-h]quinoline. Computationally derived $\mathrm{p} K_{\mathrm{aH}}$ values of quinolinoquinolines functionalized with dimethylamino $\left(\mathrm{NMe}_{2}\right)$, 1,1,3,3-tetramethylguanidino $\left(\mathrm{N}=\mathrm{C}\left(\mathrm{NMe}_{2}\right)_{2}\right)$ or $N, N, N^{\prime}, N^{\prime}, N^{\prime \prime}, N^{\prime \prime}$-hexamethylphosphorimidic triamido $\left(\mathrm{N}=\mathrm{P}\left(\mathrm{NMe}_{2}\right)_{3}\right)$ groups are significantly greater than those of quinolino[7,8-h] quinoline. Overall, electron-donating functionalities are observed to increase the basicity of the quinolinoquinoline moiety, while the substitution of electron-withdrawing groups lowers the basicity.

\section{INTRODUCTION}

The discovery of 1,8 -bis(dimethylaminonaphthalene) (DMAN) 1 (Figure 1), the original Proton Sponge, ${ }^{1}$ ignited an intense interest in neutral organic superbases. ${ }^{2-4}$ The close proximity of the lone pair of electrons on the proximal nitrogen atoms causes a destabilizing electrostatic interaction that can be alleviated by the coordination of a proton. The neutral species<smiles>CN(C)c1cccc2cccc(N(C)C)c12</smiles>

DMAN

1

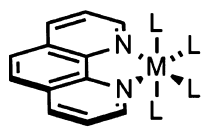

4<smiles>c1cnc2c(c1)ccc1ccc3cccnc3c12</smiles>

quinolino[7,8-h]quinoline 2

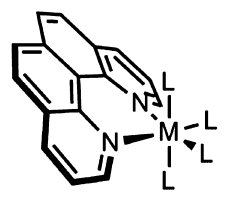

5

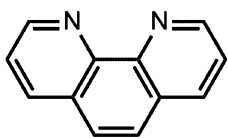

1,10-phenanthroline 3

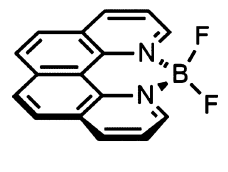

6
Figure 1. Structures of DMAN (1), quinolino[7,8-h]quinoline (2), 1,10-phenanthroline (3), 1,10-phenanthroline coordination (4), quinolino[7,8-h] quinoline coordination (5), and quinolino $[7,8-h]$ quinoline coordination to boron (6). display helical distortion to ameliorate the lone pair interaction, while the protonated species become planar. This has led to the preparation of a wide range of analogous organic superbases comprising various nitrogen and/or phosphorus functional groups held in close proximity. ${ }^{5-7}$ The unique chemistry of these molecules has seen them being used as models for the study of a variety of theories of bonding and reactivity. ${ }^{8-13}$

One area that has seen less study is the coordination of such compounds to metals. ${ }^{14-18}$ Only one complex of DMAN 1 itself has been reported. ${ }^{19}$ The methyl groups cause unfavorable interactions, destabilizing metal complexes. It goes without saying that diamines are the archetypal bidentate ligand, and so, there has been interest in using superbasic compounds as ligands in order to create reactive complexes. At first glance, the quinolinoquinoline system 2 appears to combine both concepts. The nitrogen lone pairs are forced together, giving the basic properties, but by including the nitrogen in an aromatic system, the destabilizing steric effects of the methyl groups have been removed. Arguably, the closest analogue to 2

Received: June 16, 2020

Published: July 30, 2020 
is 1,10-phenanthroline 3, a ubiquitous ligand in coordination chemistry. $^{20,21}$ However, while there are $>45,000$ hits in SciFinder for unsubstituted phenanthroline-metal complexes, there are less than 20 for quinolinoquinolines (with any substitution pattern). ${ }^{22}$

There are undoubtedly two compelling reasons for this disparity. The first is one of access. The synthesis of quinolinoquinoline $\mathbf{2}$ and its derivatives is not simple, and there has been a low supply of these compounds. ${ }^{16,23-27}$ The second relates to coordination environment. The fivemembered ring formed on coordination of phenanthroline to a metal 4 can accommodate a wide range of metals with little distortion to either the ligand or the metal. The same cannot be said for quinolinoquinolines. ${ }^{28-30}$ Coordination of a metal results in the formation of six-membered ring 5 that can only include small metals such as beryllium or boron 6 , if there is not to be significant distortion of either the ligand or the metal. ${ }^{16,28,30}$ The few examples of metal coordination to quinolinoquinolines suggests that these complexes could be useful catalyst precursors. ${ }^{15,17}$ The high basicity appears to impart a degree of thermal stability, while the out-of-plane complexation (5, M $=\mathrm{Pt}$ or $\mathrm{Re}$ ) should make one coordination site more accessible for reaction. ${ }^{15}$ It is clear that there needs to be more study of these compounds.

Given that there is clearly an opportunity to exploit this understudied system we wanted to develop chemistry that would allow access to a range of substituted quinolinoquinolines. This would permit us to pursue our interests in the coordination of small metals, ${ }^{31}$ catalysis, ${ }^{32,33}$ supramolecular chemistry, ${ }^{34-36}$ and the synthesis of unusual heterocycles. ${ }^{37-39}$

This paper outlines the current state of syntheses of substituted quinolinoquinolines. ${ }^{16,17,23-26}$ As the basicity of these compounds influences their synthesis and complexation, a study of the basicity of these compounds as determined by $\mathrm{p} K_{\mathrm{aH}}$ values would be highly informative, and thus, an investigation of both computationally derived and experimentally obtained $\mathrm{p} K_{\mathrm{aH}}$ values has been undertaken and are provided.

\section{RESULTS AND DISCUSSION}

Naming and Numbering. Quinolino[7,8-h]quinoline is a fused ring system, considered to be two quinoline heterocyclic ring systems fused together. While prior publications have used the prefix quino- for the quinoline ring system, ${ }^{15-17,23-26,40,41}$ we have adopted the quinolino- nomenclature because of updated IUPAC recommendations no longer listing quino- as an accepted contracted prefix. ${ }^{42}$ The naming of this compound is based on the numbering of the parent and substituent quinoline molecules (Figure $2 \mathrm{a}$ ). ${ }^{43-45}$ Fusion occurs at the face

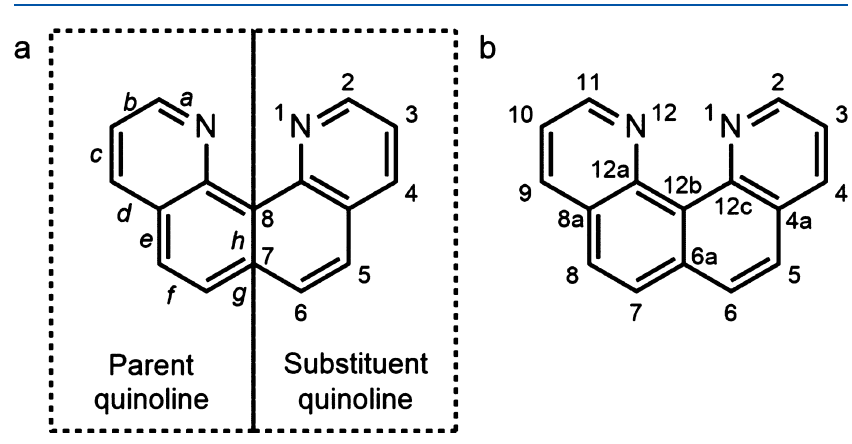

Figure 2. (a) Determination of the nomenclature of quinolino[7,8$h]$ quinoline and (b) atom numbering scheme. or two-atom bond, labeled $h$ on the parent quinoline. The numbers 7 and 8 designate the fused atoms of the attached quinoline substituent. To number the atoms of quinolino[ $[7,8$ $h$ ] quinoline, the molecular structure is oriented so that the greatest number of rings are located in the upper right quadrant, and the heteroatoms are assigned the lowest possible position numbers. Numbering then begins on the most counterclockwise atom of the top right ring and proceeds in a clockwise direction around the molecule (Figure $2 \mathrm{~b}$ ). Bridgehead carbon atoms are not formally numbered and are instead given the number of the preceding nonfused carbon atom followed by a letter (starting with "a" for an adjacent carbon atom). ${ }^{43-45}$

Synthesis of the Quinolinoquinoline Core. The synthesis of quinolinoquinolines of the type 7 is not trivial as revealed by the checkered history of these compounds (Figure 3 ). There have been a number of reported syntheses ${ }^{46}$ that have not stood up to scrutiny. ${ }^{40}$

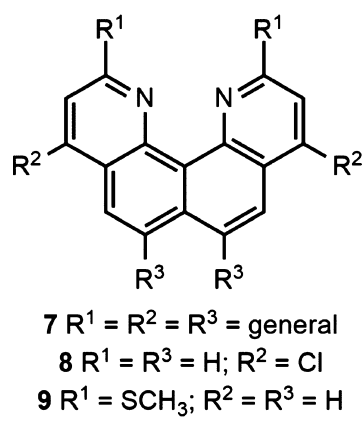

Figure 3. Structure of quinolino $[7,8-h]$ quinoline derivatives.

It is widely accepted that the first synthesis of these quinolinoquinolines $\left(8 \mathrm{R}^{1}=\mathrm{R}^{3}=\mathrm{H} ; \mathrm{R}^{2}=\mathrm{Cl}\right.$; and $2 \mathrm{R}^{1}=\mathrm{R}^{2}$ $=\mathrm{R}^{3}=\mathrm{H}$ ) was by Zirnstein and Staab. ${ }^{25,26}$ The chloro derivative was first coordinated to a metal, platinum and rhenium, some 15 years later. ${ }^{15}$ There was no mention of these compounds in the synthetic literature until a new route to 2(methylthio)quinolines (9 $\mathrm{R}^{1}=\mathrm{SCH}_{3}, \mathrm{R}^{2}=\mathrm{R}^{3}=\mathrm{H}$ ) was reported in $2004,{ }^{47}$ and an improvement on the cyclisation step of the original synthesis was detailed in $2007 .^{48}$ The former route looked attractive as the sulfide group presents a handle for modification. ${ }^{49-56}$ Unfortunately, we have been unable to repeat this chemistry and suspect that the reaction halted after a single cyclisation and acetylation. ${ }^{24}$

With all this in mind, the goal of our research was to access larger quantities of quinolinoquinolines that contained a handle for subsequent functionalization. This would enable us to study their coordination properties, tune their basicity and alter undesirable physical properties such as their low solubility. In order to elaborate the basic quinolinoquinoline core, we required suitable functionality. The previous syntheses of such orthofused quinolines deliver ester groups at the 2,11 positions and ketones at the 4,9 positions (12; Scheme 1). This seemed ideal for our purposes.

The synthesis of orthofused quinoline $\mathbf{1 2}$ was achieved following the original Honda procedure (Scheme 1). ${ }^{41}$ Mixing 1,8-diaminonapthalene $\mathbf{1 0}$ with two equivalents of dimethyl acetylenedicarboxylate in ethanol furnishes the difumarate $\mathbf{1 1}$ as a yellow precipitate that, after a simple wash, can be used in the cyclization step. The addition of 11 to biphenyl ether at $250{ }^{\circ} \mathrm{C}$ followed by stirring for $20 \mathrm{~min}$ resulted in the expected product 
Scheme 1. Synthesis of the Chloroquinoline 13

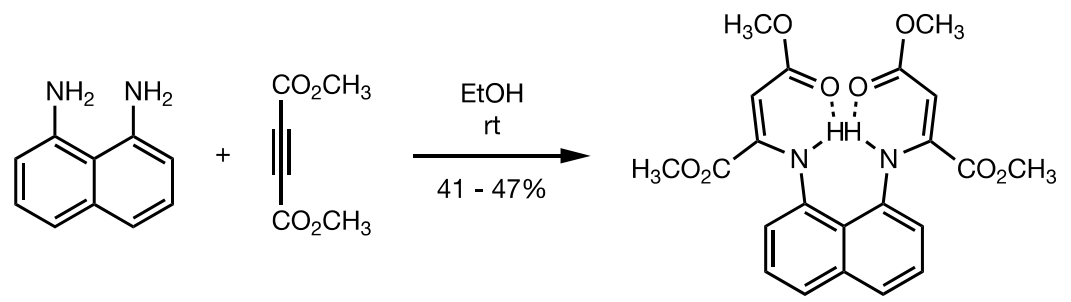<smiles>CC(=O)c1cc(Cl)c2ccc3ccc4c(Cl)cc(C(C)=O)nc4c3c2n1</smiles>

13

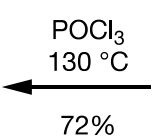<smiles></smiles>

12

Scheme 2. Synthesis of Halogen Derivatives 16 and 17

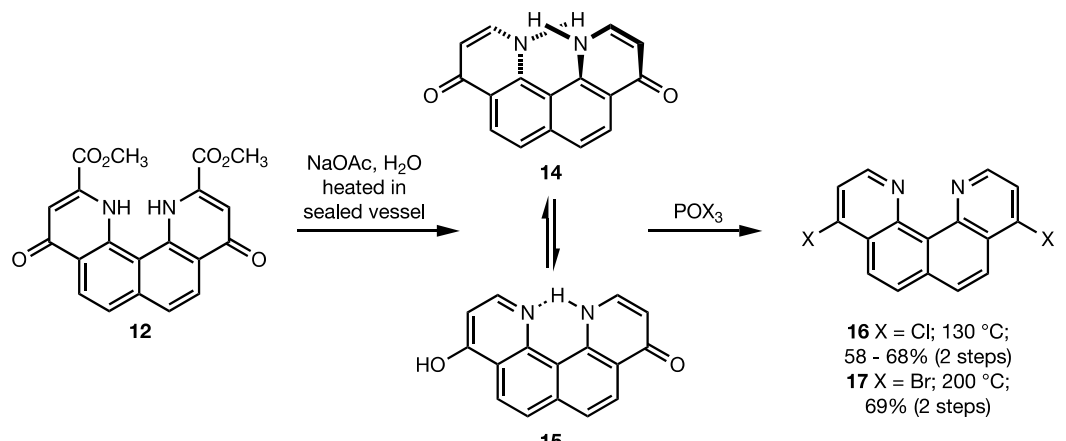

\section{Scheme 3. Synthesis of Quinolinones 18 and 19}<smiles></smiles><smiles>C[13CH2]NC(=O)[C@H](C)N(C)c1ccnc2c1ccc1ccc3c(=O)cc[nH]c3c12</smiles>

19

of aromatic electrophilic substitution. Again, purification was simplified by the relative insolubility of the product; filtration and washing give the product with sufficient purity to obtain microanalytical data and ${ }^{1} \mathrm{H}$ NMR in deuterated trifluoroacetic acid.

Functionalization of the Quinolinoquinoline Core. The functionalization of the pyridinone-like tetracycle 12 was problematic because of its poor solubility. Two transformations have proven high yielding. The first was aromatization/ dehydration by treatment with phosphorus oxychloride to give the chloroquinoline 13. A protonated version of this compound was fully characterized including X-ray crystallographic data. ${ }^{24}$ It shows the expected planar arrangement with an internal hydrogen bond between the ester carbonyl and the proton. So far, all attempts to derivatize this molecule by either reducing the esters or substituting the chlorine atoms have met with failure. Even so, to the best of our knowledge, this remains the only 2,11-disubstituted quinolinoquinoline that is capable of more than bidentate coordination and as such shows potential for future study.

The second transformation involves hydrolysis and decarboxylation to give the orthofused quinolinone (Scheme 2). 
When we started this research, this step represented the bottleneck for the synthesis of quinolinoquinolines: the reported procedure involved hydrolysis followed by a high temperature $\left(370{ }^{\circ} \mathrm{C}\right)$ and low-pressure decarboxylation $\left(10^{-5}\right.$ Torr) performed in a sublimation apparatus. We have developed a two-step, "one-pot" reaction based on chemistry by Strauss and Trainor ${ }^{57}$ that permits this transformation to be achieved far more readily. Heating a mixture of diester 12 and sodium acetate in water to $250{ }^{\circ} \mathrm{C}$ for $1 \mathrm{~h}$ in a microwave reactor gives $\mathbf{1 5}$ of sufficient purity that it can be purified after the subsequent aromatization reaction (Scheme 2). ${ }^{16}$ While reaction in a microwave is convenient, we found it easier to scale the reaction by performing it under conventional heating in a Teflon-lined stainless steel sealed vessel over a period of 12-16 h. ${ }^{16}$ Chlorination with phosphorus oxychloride delivered the orthofused quinolinoquinoline 16 in good yield for the two steps. Alternatively, the bromide 17 could be formed by treatment with phosphorus oxybromide. This compound is more reactive than the chloride. Initial attempts to hydrolyze $\mathbf{1 7}$ in aqueous dimethylamine gave the substituted and hydrolyzed dimethylamino quinolinone $\mathbf{1 8}$ (Scheme 3). In the absence of dimethylamine, 17 readily undergoes a single hydrolysis to give the nonsymmetric quinolinone 19 . Calculations show that keto-19 as drawn is $16.4 \mathrm{kcal} \mathrm{mol}^{-1}$ more stable than enol-19.

The previous synthesis of $\mathbf{1 6}$ suggested that the intermediate is the orthofused quinolinone $14 .^{25}$ While we have not fully characterized this molecule, infrared spectroscopy would suggest that the tautomer, 15, predominates. ${ }^{16}$ In addition, our calculations at the B3LYP/6-31+G(d,p) level show that 15 is by $12.0 \mathrm{kcal} \mathrm{mol}^{-1}$ more stable than 14 and by $17.6 \mathrm{kcal}$ $\mathrm{mol}^{-1}$ than a potential 4,9-dihydroxy tautomer, thus confirming the experiments. This tautomer maximizes aromaticity and minimizes structural distortions. The orthofused quinolinone forces two hydrogen atoms into close proximity and arrangement that can only be accommodated if the molecule adopts a helical twist. Based on computational modeling, the torsional angle for this helical twist in 14 is $22.0^{\circ}$. Tautomerization leads to a planar structure and would be in keeping with subsequent results.

Interestingly, Staab and co-workers ${ }^{26}$ reported that the dechlorinated derivative $\mathbf{2}$ is planar in the solid state. This is unusual for molecules with a "proton sponge"-like structure, where the lone pair interactions distort the core to give a helical twist to the molecule. After inspection of the data, it is almost certain that hydrogen bonding between 2 and a bridging water molecule alleviates unfavorable interactions. X-ray crystallographic analysis of crystals of $\mathbf{1 6}$ grown under anhydrous conditions reveal this molecule to have the expected distortion in the solid state of $20.02(9)^{\circ}$ (Figure 4a). ${ }^{16}$ Protonation of 16 stops the unfavorable lone pair interactions and gives a planar species (Figure $4 \mathrm{~b}$ ). This is confirmed by our computational analysis, which shows that in $\mathbf{1 6}$ the helical torsional twist is $21.1^{\circ}$, indicating nonplanarity. Upon protonation, in $16 \mathrm{H}^{+}$the same dihedral angle assumes $0.0^{\circ}$, thus clearly indicating the planarization.

Nucleophilic Substitution of Halogen-Appended Derivatives. We first investigated the substitution of the chlorides in the hope that this would improve the limited solubility of $\mathbf{1 6}$ as well as allowing the basicity to be tuned. Indeed, our calculations shows that the gas-phase proton affinity (PA) of the parent 2 is reduced from 255.4 to $251.0 \mathrm{kcal}$ $\mathrm{mol}^{-1}$ when two chlorine atoms are introduced as in 16 . Yet,
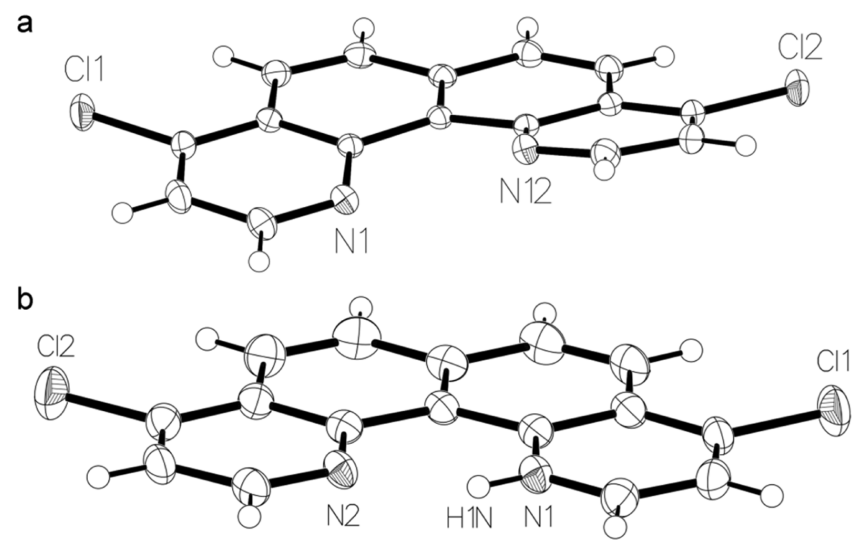

Figure 4. X-ray crystal structures of the neutral (a) and protonated (b) forms of 16. Chloroform solvent molecules for (a) and the tetrafluoroborate counter ion for (b) have been removed for clarity, ellipsoids are drawn at the $50 \%$ probability level. ${ }^{16}$

when the latter is substituted by an electron-donating group, such as the dimethylamino moiety, the resulting PA increases to $269.0 \mathrm{kcal} \mathrm{mol}^{-1}$ (see later). Formation of aromatic ethers and amines was attempted using the methodology of Schmittel. ${ }^{58}$ The reaction of 16 with 4-tert-butylphenol and $\mathrm{KOH}$ furnishes the nonsymmetric monoether $\mathbf{2 0}$ in which one of the chlorides has been hydrolyzed to give the quinolinone tautomer (Scheme 4). Subsequent reaction with phosphorus oxychloride yields the monochloride $21 .^{24}$ The more nucleophilic toluidine does not require external base and furnishes either the monoimine $\mathbf{2 2}$ or the product of double displacement 23 , depending on whether the reaction is performed in toluene or a melt formed from neat toluidine at $150{ }^{\circ} \mathrm{C}$. A similar reaction delivered the highly fluorescent ester derivative $24 .^{24}$ In each case, addition results in the formation of a tautomer in which the disfavored lone pair interactions are ameliorated by protonation.

Similar chemistry permits the synthesis of alkyl ethers and amines as well. With a strong nucleophile, such as sodium methoxide, the dichloro-derivative $\mathbf{1 6}$ was used but for the less nucleophilic amine the more reactive dibromide 17 was required (Scheme 5).

We were also interested in making a water-soluble quinolinoquinoline by substituting the chloride groups of $\mathbf{1 6}$ with sulfonic acid moieties via reaction with sodium sulfite. While the mass spectrum of the reaction mixture showed some disubstitution of the chloride groups, the only stable product formed over a range of reaction conditions was the monosulfonate 27 (Scheme 6). NMR analysis confirmed the formation of 27 rather than the phenol tautomer. This was supported by our calculations, which showed 27 is $15.3 \mathrm{kcal}$ $\mathrm{mol}^{-1}$ more stable than the phenol tautomer.

Palladium-Catalyzed Cross-Coupling Reactions. Formation of the dibromide $\mathbf{1 7}$ opened the door for palladiumcatalyzed cross-coupling reactions as a route to functionalize the quinolinoquinoline core. Our initial attempts utilized 4pyridineboronic acid pinacol ester as the coupling partner. Under typical Suzuki-Miyaura reaction conditions using $\mathrm{Pd}\left(\mathrm{PPh}_{3}\right)_{4}$ as the precatalyst, $\mathrm{Cs}_{2} \mathrm{CO}_{3}$ as the base, and a mixture of 1,4-dioxane and water as the solvent, the monopyridine derivative 28 could be isolated in $96 \%$ yield (Scheme 7). X-ray crystallographic analysis of $\mathbf{2 8}$ confirms that the quinolinone tautomer is formed (Figure S1). The water was included in the mistaken belief that it would increase the rate of 
Scheme 4. Nucleophilic Substitution of 16 with Oxygen and Nitrogen Donors

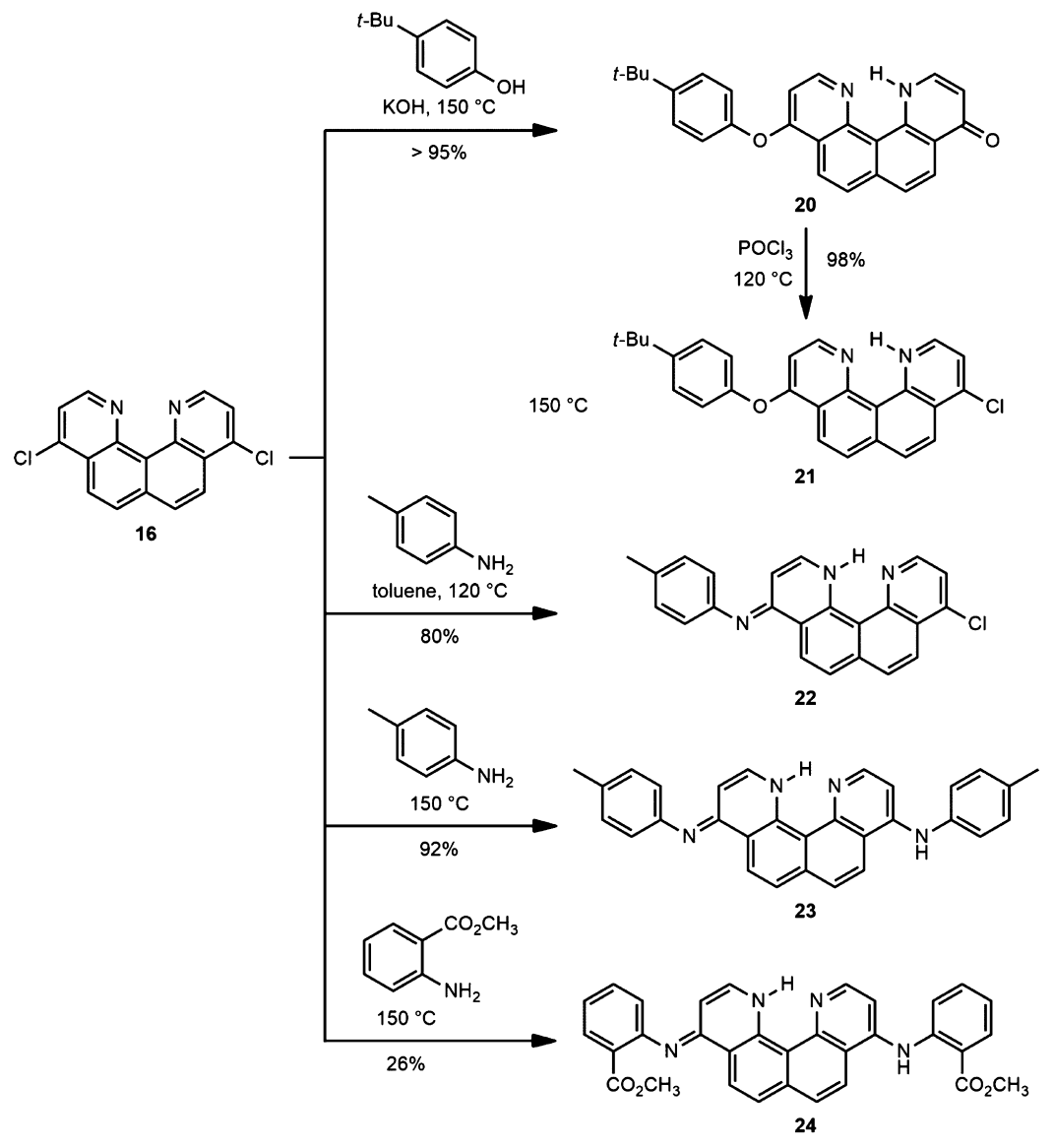

Scheme 5. Synthesis of 25 and 26 by Nucleophilic Substitution

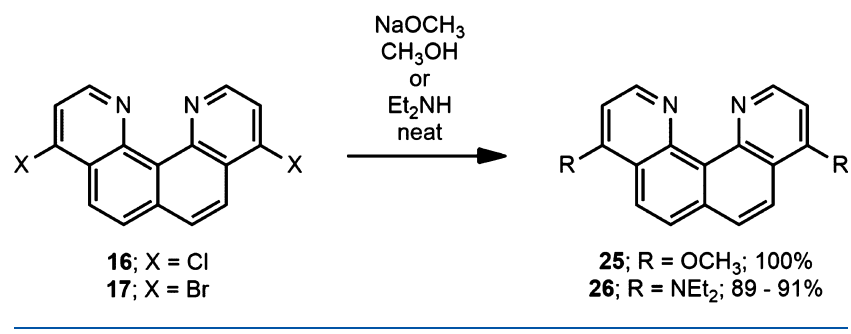

Scheme 6. Synthesis of the Monosulfonate Quinolinone 27

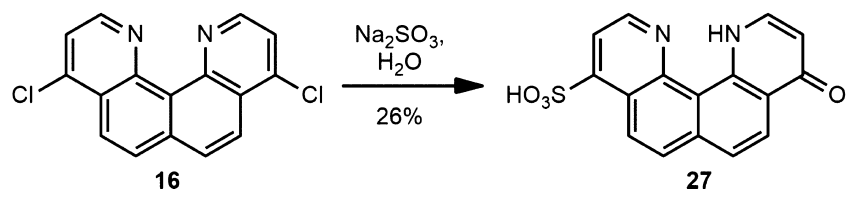

reaction either by affecting the hydrolysis of the boron ester or promoting the formation of either the boronate or oxopalladium species. ${ }^{59}$ With hindsight, it is clear that the addition of water leads to the hydrolysis of one bromide to form the hydrogen bond-stabilized quinolinone. The second, activated, bromide then participates in the cross-coupling reaction.

Performing the reaction under anhydrous conditions with dry dimethylformamide as a solvent led to the desired dipyridine 29. For the 4-pyridine derivative, moderate conversion was observed $(\sim 60 \%)$ along with formation of a small quantity of the monopyridine derivative 28 . Purification was problematic with the only success being achieved with fractional crystallization, which gave a disappointing $26 \%$ of the pure material.

The structure of the compound 29 was confirmed by X-ray crystallography (Figure 5). This shows the expected helical twist in the quinolinoquinoline core, as the nitrogen lone pairs minimize interaction. The helical torsional twist is significantly greater at $24.19(12)^{\circ}$ than that observed in the dichloro derivative $16\left(20.02(9)^{\circ}\right)$. This is in excellent agreement with the calculated helical torsional twist of $23.3^{\circ}$. The pyridyl side groups are each twisted at $63.29^{\circ}$ angles to the mean central plane and sit almost perpendicularly with respect to each other $\left(83.01^{\circ}\right)$. The divergent angle of these pyridine groups will prevent coordination to the same metal ion.

Similarly, it is possible to prepare the di-3-pyridine derivative 30 utilizing the anhydrous coupling conditions. Fractional crystallization results in a yield of $30 \%$.

The monopyridine quinolinone $\mathbf{2 8}$ can be primed for a second coupling reaction by bromination. This would allow the preparation of nonsymmetric quinolinoquinolines. Simply resubjecting this compound to the standard bromination conditions gave the desired quinolinoquinoline 31 in $54 \%$ yield (Scheme 8).

Electrophilic Aromatic Substitution Reactions. Having investigated substitution at the 2,11- and 4,9-positions, we were also interested in functionalization of the 6,7-positions of the core. One of the simplest methods is electrophilic aromatic substitutions such as nitration. Such chemistry would install a nitrogen atom into the molecule that might permit further functionalization at a later stage. The addition of dichloride $\mathbf{1 6}$ 
Scheme 7. Synthesis of 3-Pyridine and 4-Pyridine Functionalized Quinolinoquinolines via Palladium-Catalyzed Cross-Coupling Reactions

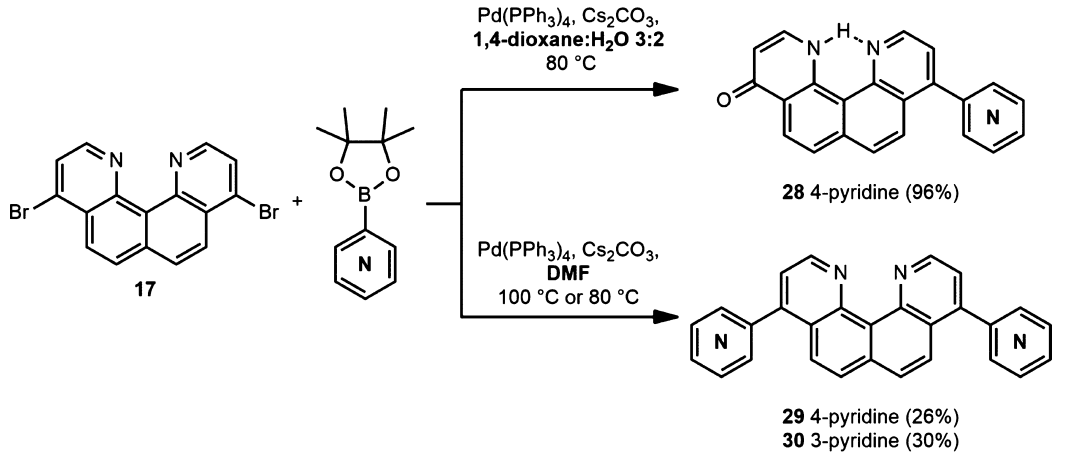

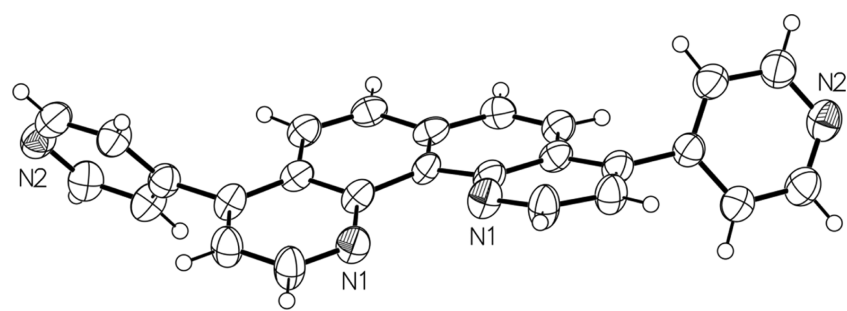

Figure 5. X-ray crystal structure of 29; ellipsoids are drawn at the $50 \%$ probability level.

Scheme 8. Synthesis of the Nonsymmetric Quinolinoquinoline 31

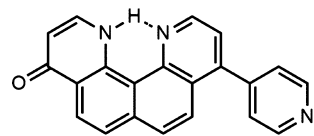

28
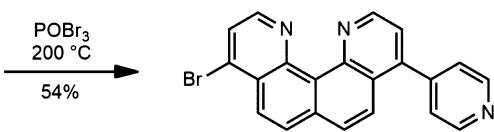

31 to a preheated mixture of fuming nitric acid and concentrated sulfuric acid for just 2 min gave the dinitro compound 32 in $35 \%$ yield (Scheme 9 ). All data suggests the formation of this isomer, but not unexpectedly, this derivative shows limited solubility and characterization has been challenging. Mass spectroscopy confirms this composition.

Eventually, we were able to grow crystals suitable for X-ray crystallographic analysis (Figure S3). These crystals indicated hydrolysis of one of the chloro substituents occurred during recrystallization. As expected, once hydrolysis occurs, the planar hydrogen bond stabilized quinolinone tautomer 33 is formed. Because of this compound being the unsought hydrolysis product, no further characterization was attempted.

The work above presents the most comprehensive study of orthofused quinoline proton sponge analogues to date. We have shown that a functionalized core can be readily accessed in synthetically useful quantities. The halogenated derivatives, 16 and 17 , act as good precursors to a range of new compounds.
This will permit the basicity of this system to be fine-tuned as well as the development of new and useful materials.

Throughout the synthetic studies the propensity for these compounds to undergo hydrolysis and form a hydrogen bondstabilized orthofused quinolinoquinolinone system has plagued efficient transformations. We suspect that the basic nature of these proton sponge analogues leads to protonation of the nitrogen and activation of one of the halogen atoms. To gain more insight into the basicity of this core, experimental and computational studies were undertaken on a number of the derivatives.

Experimental Basicity Studies. The methodology and experimental set up for the quinolinoquinoline derivatives in acetonitrile was essentially the same as in previous publications. ${ }^{60,61}$ The terminology $\mathrm{p} K_{\mathrm{aH}}$ has been used to express the basicity of each base, rather than $\mathrm{p} K_{\mathrm{a}}$, to clearly express that it refers to the protonation of a base (or deprotonation of the protonated base). ${ }^{62}$ The determined $\mathrm{p} K_{\mathrm{aH}}$ values for quinolino$[7,8-h]$ quinoline and its derivatives are given in Table 1 . A superbase has occasionally been defined as a base with $\mathrm{p} K_{\mathrm{aH}}$ value of the conjugate acid greater than that of the proton sponge DMAN. ${ }^{2}$ The $\mathrm{pK} \mathrm{aH}_{\mathrm{aH}}$ of DMAN in acetonitrile is 18.63 . $^{62}$ Based on this definition, two of the compounds for which $\mathrm{p} K_{\mathrm{aH}}$ was measured had values consistent with that of a superbase. The assigned $\mathrm{p} K_{\mathrm{aH}}$ for quinolino[7,8-h] quinoline was $19.60,{ }^{62}$ greater than that of DMAN in acetonitrile. The diamine derivative 26 had a higher $\mathrm{p} K_{\mathrm{aH}}$ of 23.97 , suggesting an even greater ability to act as a superbase. The increased basicity of $\mathbf{2 6}$ compared to quinolino $[7,8-h]$ quinoline is likely because of the activating diethylamino groups which increase electron delocalization and help to stabilize the positive charge of the conjugate acid.

Compounds 16 and 17 both had experimentally determined $\mathrm{p} K_{\mathrm{aH}}$ values slightly less than that of DMAN, while the $\mathrm{p} K_{\mathrm{aH}}$ values of 13, 15, and 20 were significantly lower. Therefore, these five quinolino[7,8-h]quinoline derivatives cannot be classified as superbases. The quinolinoquinoline derivatives 13, 16, and 17 contain deactivating groups which would destabilize the conjugate acid by withdrawing electron density

Scheme 9. Synthesis of the Dinitro Quinolinoquinoline 32 and Subsequent Hydrolysis

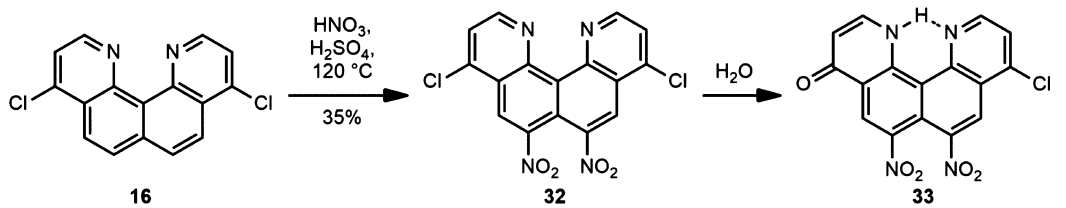


Table 1. Experimentally Determined $\mathrm{pK}_{\mathrm{aH}}$ in Acetonitrile and Calculated PAs, GBs, and $\mathrm{p} K_{\mathrm{aH}}$ in Acetonitrile for Quinolinoquinoline Derivatives

\begin{tabular}{|c|c|c|c|c|c|}
\hline \multirow[b]{2}{*}{ structure } & \multirow[b]{2}{*}{ functionality } & \multirow{2}{*}{$\frac{\text { experimental }}{\mathrm{p} K_{\mathrm{aH}}}$} & \multicolumn{3}{|c|}{ calculated } \\
\hline & & & $\mathrm{PA}\left(\mathrm{kcal} \mathrm{mol}{ }^{-1}\right)$ & GB $\left(\mathrm{kcal} \mathrm{mol}{ }^{-1}\right)$ & $\mathrm{p} K_{\mathrm{aH}}$ \\
\hline 2 & $\mathrm{R}^{1}=\mathrm{R}^{2}=\mathrm{R}^{3}=\mathrm{H}$ & 19.60 & 255.4 & 246.8 & 19.6 \\
\hline 13 & $\mathrm{R}^{1}=\mathrm{CO}_{2} \mathrm{CH}_{3}, \mathrm{R}^{2}=\mathrm{Cl}, \mathrm{R}^{3}=\mathrm{H}$ & 9.24 & 248.8 & 240.8 & 9.9 \\
\hline $15^{a}$ & $\mathrm{R}^{1}=\mathrm{R}^{3}=\mathrm{H}, \mathrm{R}^{2}=\mathrm{OH}$ & 12.21 & 242.9 & 235.0 & 12.4 \\
\hline 16 & $\mathrm{R}^{1}=\mathrm{R}^{3}=\mathrm{H}, \mathrm{R}^{2}=\mathrm{Cl}$ & 17.64 & 251.0 & 243.0 & 17.3 \\
\hline 17 & $\mathrm{R}^{1}=\mathrm{R}^{3}=\mathrm{H}, \mathrm{R}^{2}=\mathrm{Br}$ & 17.58 & 250.8 & 242.2 & 17.2 \\
\hline $20^{b}$ & $\mathrm{R}^{1}=\mathrm{R}^{3}=\mathrm{H}, \mathrm{R}^{2}-1=4-\mathrm{tBu}-\mathrm{PhO}, \mathrm{R}^{2}-2=\mathrm{OH}$ & 12.10 & 245.4 & 237.2 & 12.5 \\
\hline 26 & $\mathrm{R}^{1}=\mathrm{R}^{3}=\mathrm{H}, \mathrm{R}^{2}=\mathrm{NEt}_{2}$ & 23.97 & 269.5 & 260.8 & 23.0 \\
\hline 32 & $\mathrm{R}^{1}=\mathrm{H}, \mathrm{R}^{2}=\mathrm{Cl}, \mathrm{R}^{3}=\mathrm{NO}_{2}$ & & 236.4 & 228.3 & 12.1 \\
\hline I & $\mathrm{R}^{1}=\mathrm{NMe}_{2}, \mathrm{R}^{2}=\mathrm{R}^{3}=\mathrm{H}$ & & 259.8 & 251.6 & 20.3 \\
\hline II & $\mathrm{R}^{1}=\mathrm{N}=\mathrm{C}\left(\mathrm{NMe}_{2}\right)_{2}, \mathrm{R}^{2}=\mathrm{R}^{3}=\mathrm{H}$ & & 281.4 & 272.6 & 29.9 \\
\hline III & $\mathrm{R}^{1}=\mathrm{N}=\mathrm{P}\left(\mathrm{NMe}_{2}\right)_{3}, \mathrm{R}^{2}=\mathrm{R}^{3}=\mathrm{H}$ & & 286.6 & 280.7 & 31.4 \\
\hline IV & $\mathrm{R}^{1}=\mathrm{R}^{3}=\mathrm{H}, \mathrm{R}^{2}=\mathrm{NMe}_{2}$ & & 269.0 & 261.4 & 23.6 \\
\hline V & $\mathrm{R}^{1}=\mathrm{R}^{3}=\mathrm{H}, \mathrm{R}^{2}=\mathrm{N}=\mathrm{C}\left(\mathrm{NMe}_{2}\right)_{2}$ & & 279.3 & 273.3 & 26.0 \\
\hline VI & $\mathrm{R}^{1}=\mathrm{R}^{3}=\mathrm{H}, \mathrm{R}^{2}=\mathrm{N}=\mathrm{P}\left(\mathrm{NMe}_{2}\right)_{3}$ & & 290.6 & 283.2 & 29.6 \\
\hline VII & $\mathrm{R}^{1}=\mathrm{R}^{2}=\mathrm{H}, \mathrm{R}^{3}=\mathrm{NMe}_{2}$ & & 262.8 & 254.9 & 20.8 \\
\hline VIII & $\mathrm{R}^{1}=\mathrm{R}^{2}=\mathrm{H}, \mathrm{R}^{3}=\mathrm{N}=\mathrm{C}\left(\mathrm{NMe}_{2}\right)_{2}$ & & 271.7 & 264.9 & 22.5 \\
\hline IX & $\mathrm{R}^{1}=\mathrm{R}^{2}=\mathrm{H}, \mathrm{R}^{3}=\mathrm{N}=\mathrm{P}\left(\mathrm{NMe}_{2}\right)_{3}$ & & 275.9 & 269.3 & 23.0 \\
\hline $\mathrm{X}$ & $\mathrm{R}^{1}=\mathrm{R}^{2}=\mathrm{R}^{3}=\mathrm{NMe}_{2}$ & & 273.8 & 266.4 & 24.2 \\
\hline $\mathrm{XI}$ & $\mathrm{R}^{1}=\mathrm{R}^{2}=\mathrm{R}^{3}=\mathrm{N}=\mathrm{C}\left(\mathrm{NMe}_{2}\right)_{2}$ & & 298.1 & 290.6 & 33.1 \\
\hline XII & $\mathrm{R}^{1}=\mathrm{R}^{2}=\mathrm{R}^{3}=\mathrm{N}=\mathrm{P}\left(\mathrm{NMe}_{2}\right)_{3}$ & & 303.3 & 295.8 & 35.5 \\
\hline
\end{tabular}

${ }^{a}$ Neutral base exists as the quinolinone tautomer 15 in Scheme 2. ${ }^{b}$ Neutral base exists as the quinolinone tautomer 20 in Scheme 4.

from the aromatic system. The $-\mathrm{CO}_{2} \mathrm{CH}_{3}$ group in $\mathbf{1 3}$ is a stronger deactivating group than the halogens in 16 and 17, accounting for its lower basicity. The reduced basicity in $\mathbf{1 5}$ and 20 can be attributed to the increased stability of the neutral base because of prototropic tautomerism, involving the proton transfer from an $-\mathrm{OH}$ group to the pyridine nitrogen.

We also investigated the effect of the angle of the helical torsional twist on the $\mathrm{pK}_{\mathrm{aH}}$ of quinolino[7,8-h]quinoline derivatives. Computational analysis reveals the most basic derivative, 26, has a change in torsional angle from 29.1 to $5.0^{\circ}$ upon protonation. However, 13 has a similar calculated helical torsional twist of $28.4^{\circ}$ in the neutral base and $6.0^{\circ}$ in the protonated form and yet has a significantly lower basicity. Both 15 and 20 are planar structures because of the prototropic tautomerisation, and yet, they record higher $\mathrm{p} K_{\mathrm{aH}}$ values in comparison to 13 . The neutral bases of 2,16 , and 17 have torsional angles of $17.3,21.1$, and $19.0^{\circ}$, respectively, which do not correlate with the respective $\mathrm{p} K_{\mathrm{aH}}$ values. Looking at all factors, it appears the size of the helical torsional twist of the neutral base does not affect the basicity of quinolino[7,8$h]$ quinoline derivatives. Instead, the basicity is heavily dependent on the presence of electron-withdrawing or electrondonating groups.

Computational Basicity Studies. Next, we investigated the basicities of other quinolino $[7,8-h]$ quinoline derivatives yet to be synthesized and compared those with some of the systems reported here. By functionalizing 2 with electron-donating dimethylamino $\left(\mathrm{NMe}_{2}\right)$, 1,1,3,3-tetramethylguanidino $(\mathrm{N}=$
$\left.\mathrm{C}\left(\mathrm{NMe}_{2}\right)_{2}\right)$, or $N, N, N^{\prime}, N^{\prime}, N^{\prime \prime}, N^{\prime \prime}$-hexamethylphosphorimidic triamido $\left(\mathrm{N}=\mathrm{P}\left(\mathrm{NMe}_{2}\right)_{3}\right)$ groups we hoped to further improve the basicity of the quinolino $[7,8-h]$ quinoline motif. Structures with these functionalities at the $\mathrm{R}^{1}, \mathrm{R}^{2}$ and/or $\mathrm{R}^{3}$ positions were modeled computationally and their gas-phase proton affinities (PAs), gas-phase basicities (GBs), and $\mathrm{pK}_{\mathrm{aH}}$ in acetonitrile calculated (Table 1).

Monoprotonation of the parent 2 to give the cation $[2-\mathrm{H}]^{+}$ has an associated PA of $255.4 \mathrm{kcal} \mathrm{mol}^{-1}$. This makes it a stronger base than DMAN $\left(\mathrm{PA}=245.8 \mathrm{kcal} \mathrm{mol}^{-1}\right),{ }^{60}$ and justifies the choice of the quinolino[7,8-h] quinoline core in the design of highly potent organic superbases. In the conjugate acid, the attached proton is placed on one of the nitrogen atoms with $d(\mathrm{~N}-\mathrm{H})=1.056 \AA$, and hydrogen-bonded to another pyridine nitrogen with $d(\mathrm{~N} \cdots \mathrm{N})=2.613 \AA, d(\mathrm{NH} \cdots \mathrm{N})=1.704$ $\AA$, and an $\mathrm{N}-\mathrm{H} \cdots \mathrm{N}$ angle of $141.2^{\circ}$. Such an asymmetry of the protonation fragment is seen in all other studied bases and is in line with earlier reports on similar systems. ${ }^{13,63}$ However, calculations at the B3LYP/6-31+G(d,p) level show that the transition state for the proton transfer from one pyridine nitrogen to another lies only $0.7 \mathrm{kcal} \mathrm{mol}^{-1}$ above the asymmetric $[2-\mathrm{H}]^{+}$, which features a single negative frequency of $1163 i \mathrm{~cm}^{-1}$ corresponding to the $\mathrm{N}-\mathrm{H} \cdots \mathrm{N} \leftrightarrow \mathrm{N} \cdots \mathrm{H}-\mathrm{N}$ vibration, resulting in a symmetrical structure with $d(\mathrm{~N} \cdots \mathrm{N})=$ $2.477 \AA$, both $d(\mathrm{NH} \cdots \mathrm{N})=1.286 \AA$, and an $\mathrm{N}-\mathrm{H} \cdots \mathrm{N}$ angle of $149.0^{\circ}$. Such a small barrier allows a spontaneous proton shuttle in solution and likely in the solid state, as it was observed earlier in related derivatives. ${ }^{64,65}$ Each of the quinolino[7,8-h]- 
quinoline derivatives had greater PAs and GBs than 2, which can be attributed to the added functionalities acting as activating groups, donating electron density to the aromatic system and further stabilizing the conjugate acid formed. Interestingly, both halogeno derivatives $\mathbf{1 6}$ and 17 are stronger bases than their hydroxyl analogue 15. This is brought about as a result of the prototropic tautomerism in the latter, involving the proton transfer from one of the $-\mathrm{OH}$ groups to the pyridine nitrogen, which stabilizes the neutral base and reduces the resulting basicity. This effect is equally seen in both the gasphase (around $8 \mathrm{kcal} \mathrm{mol}^{-1}$ ) and acetonitrile solution (around $5 \mathrm{p} K_{\mathrm{aH}}$ units). Nevertheless, attachment of further electronwithdrawing substituents, as in 32, significantly reduces the basicity, as two nitro groups at positions 6 and 7 lower both the $\mathrm{PA}$ and $\mathrm{p} K_{\mathrm{aH}}$ value by $14.6 \mathrm{kcal} \mathrm{mol}^{-1}$ and 5.2 units, respectively. The substitution of one of the $-\mathrm{OH}$ groups with the 4- $t \mathrm{Bu}-\mathrm{PhO}$ substituent, as in $\mathbf{2 0}$, reduces the magnitude of this effect and improves the basicity in the gas-phase, yet without a significant effect in the solution. Disubstituted derivatives confirm an already observed trend in which systems with the phosphazeno groups surpass the basicity of those with guanidino and dimethylamino moieties, ${ }^{7}$ being fully in line with the electron-donating ability of those substituents. This is evident in all of the corresponding triads, namely, I-III, IVVI, and VII-IX. Interestingly, the largest basicity-amplifying effect is observed when substituents are placed at the paraposition to the quinolinoquinoline nitrogen. We attribute this to the fact that at the ortho-position, despite being closer to the protonation center, the attached groups cause steric interference, which reduces their optimal effect. When placed at positions 6 and 7, the effect is diminished because of the further distance from the protonation site. Accordingly, the greatest PA of $290.6 \mathrm{kcal} \mathrm{mol}^{-1}$ was calculated for I, which also had the greatest $\mathrm{GB}$ and $\mathrm{p} K_{\mathrm{aH}}$ of disubstituted compounds. In hexasubstituted systems, the phosphazene derivative XII again dominates with the gas-phase PA exceeding the hyperbasicity limit of $300 \mathrm{kcal} \mathrm{mol}^{-1},{ }^{66}$ reaching $\mathrm{PA}=303.3 \mathrm{kcal} \mathrm{mol}^{-1}$ and $\mathrm{p} K_{\mathrm{aH}}=35.5$, being the strongest superbase investigated here.

The calculated $\mathrm{pK}_{\mathrm{aH}}$ for quinolino[7,8-h]quinoline (2) (19.6) is in excellent agreement with the literature value of $19.60{ }^{62}$ which holds for all other systems where this comparison is available (Table 1 ). This confirms the validity of the employed computational methodology and renders other results reliable as well.

\section{CONCLUSIONS}

This work provides an as-current comprehensive study of the synthesis of quinolino[ $[7,8-h]$ quinoline and its derivatives. The functionalized core can be synthesized in appreciable quantities, with the halogen derivatives $\mathbf{1 6}$ and $\mathbf{1 7}$ acting as precursors for a range of new compounds. The tendency for quinolinoquinoline compounds to hydrolyze and form hydrogen bond-stabilized quinolinone tautomers has been problematic throughout the synthetic studies. A number of new quinolino[7,8-h]quinoline derivatives have been presented, which has allowed for the investigation into the basicity of these compounds.

Quinolino[7,8-h]quinoline is already appreciably basic, surpassing both the gas-phase and acetonitrile solution basicities of DMAN, which makes it a superbasic system in both phases. The synthesized quinolinoquinoline $\mathbf{2 6}$ presented an even greater basicity than quinolino $[7,8-h]$ quinoline, with the electron-donating diethylamino groups thought to destabilize the conjugate acid. Computational studies show that careful substitution of the quinolino[7,8-h]quinoline skeleton allows fine-tuning of the resulting basicity, with electron-accepting groups reducing the basicity parameters. Electron-donating moieties increase the resulting basicity, and this effect is highest when these are introduced at positions 4 and 9, para to the quinolinoquinoline nitrogen. Several modeled compounds had calculated $\mathrm{p} K_{\mathrm{aH}}$ values greater than any experimentally determined value for a quinolino $[7,8-h]$ quinoline derivative, showing the potential for increased superbasicity of these compounds.

\section{EXPERIMENTAL SECTION}

General Procedures. Unless otherwise stated, all reagents and solvents were purchased from commercial sources and used without purification. The heat source for all syntheses was a temperaturecontrolled oil bath, with paraffin oil for temperatures less than $100^{\circ} \mathrm{C}$ and silicone oil for temperatures greater than $100{ }^{\circ} \mathrm{C}$. NMR spectra were collected on Bruker AVANCE 500 and $700 \mathrm{MHz}$ spectrometers. All chemical shifts are reported relative to the residual solvent $\left({ }^{1} \mathrm{H}\right.$, ${ }^{13} \mathrm{C}$ ). Microanalyses were performed at the Campbell Microanalytical Laboratory at the University of Otago. High-resolution mass spectra were recorded on either a micrOTOF-Q mass spectrometer, operating at a nominal voltage of $3500 \mathrm{~V}$ or a Thermo Scientific Q-Exactive Focus Hybrid Quadrupole-Orbitrap mass spectrometer. IR and UVvis spectra were recorded with a Nicolet 5700 FT-IR and a UV-1800 Shimadzu spectrophotometer, respectively.

Synthesis of 4,9-Dibromoquinolino[7,8-h]quinoline (17). Phosphorus oxybromide (2.97 g, $10.4 \mathrm{mmol})$ was added to 14 $(0.520 \mathrm{~g}, 2.08 \mathrm{mmol})$, and the reaction was stirred at $200{ }^{\circ} \mathrm{C}$ for 30 min under an atmosphere of Ar. The reaction mixture was diluted with $\mathrm{CH}_{2} \mathrm{Cl}_{2}(200 \mathrm{~mL})$ and $\mathrm{MeOH}(20 \mathrm{~mL})$ and basified with $6 \mathrm{M} \mathrm{KOH}$ $(20 \mathrm{~mL})$ in water $(200 \mathrm{~mL})$. A small portion of decolourizing carbon was added, and the organic layer was filtered and dried with $\mathrm{MgSO}_{4}$ to give $17(0.533 \mathrm{~g}, 66 \%) .{ }^{1} \mathrm{H}$ NMR $\left(500 \mathrm{MHz}, \mathrm{CDCl}_{3}\right): \delta=9.18$ (brd, $J$ $=4.7,2 \mathrm{H}), 8.51(\mathrm{~d}, J=8.9,2 \mathrm{H}), 8.09(\mathrm{~d}, J=8.9,2 \mathrm{H}), 7.94(\mathrm{~d}, J=4.7$, $2 \mathrm{H})$ ppm. ${ }^{13} \mathrm{C}\left\{{ }^{1} \mathrm{H}\right\}$ NMR $\left(125 \mathrm{MHz}, \mathrm{CDCl}_{3}\right): \delta=149.8,148.2,136.4$, $134.4,129.0,128.8,127.8,126.1,125.5 \mathrm{ppm}$. HRMS (ESI/TOF) $\mathrm{m} / \mathrm{z}$ : $[\mathrm{M}+\mathrm{H}]^{+}$calcd for $\mathrm{C}_{16} \mathrm{H}_{9} \mathrm{~N}_{2}{ }^{79} \mathrm{Br}^{81} \mathrm{Br}$, 388.9107; found, 388.9102.

Synthesis of 9-(Dimethylamino)quinolino[7,8-h]quinoline4(1H)-one (18). Dimethylamine solution ( $40 \%$ aq., $15 \mathrm{~mL}$ ) was added to $17(57 \mathrm{mg}, 0.148 \mathrm{mmol})$ and heated under reflux for 24-48 h. Water $(150 \mathrm{~mL})$ was added, and the residue was extracted with $\mathrm{CH}_{2} \mathrm{Cl}_{2}(150 \mathrm{~mL})$. The organic layer was washed with water $(2 \times 100$ $\mathrm{mL})$, dried with $\mathrm{MgSO}_{4}$, filtered, and dried in vacuo to give $18(26 \mathrm{mg}$, $60 \%) .{ }^{1} \mathrm{H}$ NMR $\left(500 \mathrm{MHz}, \mathrm{CDCl}_{3}\right): \delta=16.15(\mathrm{~s}, 1 \mathrm{H} ; \mathrm{NH}), 8.68$ (d, $J$ $=5.4 \mathrm{~Hz}, 1 \mathrm{H}), 8.58(\mathrm{~d}, J=8.6 \mathrm{~Hz}, 1 \mathrm{H}), 8.09(\mathrm{~d}, J=9.0 \mathrm{~Hz}, 1 \mathrm{H}), 7.90$ $(\mathrm{dd}, J=6.5,6.5 \mathrm{~Hz}, 1 \mathrm{H}), 7.76(\mathrm{~d}, J=9.0 \mathrm{~Hz}, 1 \mathrm{H}), 7.68(\mathrm{~d}, J=8.6 \mathrm{~Hz}$, $1 \mathrm{H}), 6.97(\mathrm{~d}, J=5.4 \mathrm{~Hz}, 1 \mathrm{H}), 6.51(\mathrm{~d}, J=6.6 \mathrm{~Hz}, 1 \mathrm{H}), 3.11(\mathrm{~s}, 6 \mathrm{H}$; $\left.\mathrm{CH}_{3}\right)$ ppm. ${ }^{13} \mathrm{C}\left\{{ }^{1} \mathrm{H}\right\}$ NMR $\left(125 \mathrm{MHz}, \mathrm{CDCl}_{3}\right): \delta=178.3,158.5$, 148.9 , 147.2, 144.1, 140.7, 137.4, 136.2, 125.8, 125.6, 124.6, 123.1, $120.5,117.6,111.5,108.1,44.1 \mathrm{ppm}$. HRMS (ESI/Orbitrap) $\mathrm{m} / \mathrm{z}:[\mathrm{M}$ $+\mathrm{H}]^{+}$calcd for $\mathrm{C}_{18} \mathrm{H}_{16} \mathrm{~N}_{3} \mathrm{O}$, 290.1288; found, 290.1278.

Synthesis of 9-Bromoquinolino[7,8-h]quinoline-4(1H)-one (19). A $2: 3 \mathrm{MeOH} / \mathrm{H}_{2} \mathrm{O}(5 \mathrm{~mL})$ was added to $17(6 \mathrm{mg}, 0.0155$ $\mathrm{mmol}$ ) and heated under reflux for $\sim 14 \mathrm{~h}$. The solvent was removed in vacuo and then, the precipitate was dissolved in a solution of 24:1 $\mathrm{CHCl}_{3} / \mathrm{MeOH}(25 \mathrm{~mL})$. The solution was washed with water $(3 \times 30$ $\mathrm{mL}$ ), dried with $\mathrm{MgSO}_{4}$, filtered, and dried in vacuo to give 19 (4 mg, $80 \%) .{ }^{1} \mathrm{H}$ NMR $\left(500 \mathrm{MHz}, \mathrm{CDCl}_{3}\right): \delta=15.49(\mathrm{~s}, 1 \mathrm{H} ; \mathrm{NH}), 8.85(\mathrm{~d}, J$ $=4.9 \mathrm{~Hz}, 1 \mathrm{H}), 8.77(\mathrm{~d}, J=8.6 \mathrm{~Hz}, 1 \mathrm{H}), 8.37(\mathrm{~d}, J=9.1 \mathrm{~Hz}, 1 \mathrm{H}), 8.08$ $(\mathrm{d}, J=9.1 \mathrm{~Hz} 1 \mathrm{H}), 8.01-7.98(\mathrm{~m}, 2 \mathrm{H}), 7.86(\mathrm{~d}, J=8.6 \mathrm{~Hz}, 1 \mathrm{H}), 6.61$ $(\mathrm{d}, J=7.3 \mathrm{~Hz}, 1 \mathrm{H})$ ppm. ${ }^{13} \mathrm{C}\left\{{ }^{1} \mathrm{H}\right\} \operatorname{NMR}\left(125 \mathrm{MHz}, \mathrm{CDCl}_{3}\right): \delta=$ $178.4,176.1,148.3,146.8,146.4,140.3,137.8,137.1,130.4,127.2$, $126.5,125.6,123.5,112.1,108.1 \mathrm{ppm}$. HRMS (ESI/TOF) $m / z:=[\mathrm{M}$ $+\mathrm{H}]^{+}$calcd for $\mathrm{C}_{16} \mathrm{H}_{10} \mathrm{~N}_{2} \mathrm{O}^{81} \mathrm{Br}, 326.9951$; found, 326.9975 .

Synthesis of $N^{4}, N^{4}, N^{9}, N^{9}$-Tetraethylquinolino[7,8-h]quinoline-4,9-diamine (26). Excess neat diethylamine $(20 \mathrm{~mL})$ was added to $17(100 \mathrm{mg}, 0.258 \mathrm{mmol})$ and heated under reflux for $48-72 \mathrm{~h}$. Water $(50 \mathrm{~mL})$ was added, and the residue was extracted 
with $\mathrm{CH}_{2} \mathrm{Cl}_{2}(100 \mathrm{~mL})$. The organic layer was washed with water $(3 \times$ $100 \mathrm{~mL}$ ), dried with $\mathrm{MgSO}_{4}$, filtered, and dried in vacuo to give $\mathbf{2 6}$ (86 $\mathrm{mg}, 90 \%) .{ }^{1} \mathrm{H}$ NMR $\left(500 \mathrm{MHz}, \mathrm{CDCl}_{3}\right): \delta=19.42(\mathrm{~s}, 1 \mathrm{H} ; \mathrm{NH}), 9.22$ (dd, $J=3.0,6.2 \mathrm{~Hz}, 2 \mathrm{H}), 8.23(\mathrm{~d}, J=9.1 \mathrm{~Hz}, 2 \mathrm{H}), 7.98(\mathrm{~d}, J=9.1 \mathrm{~Hz}$, $2 \mathrm{H}), 7.30(\mathrm{~d}, J=6.2 \mathrm{~Hz}, 2 \mathrm{H}), 3.68\left(\mathrm{q}, J=7.1 \mathrm{~Hz}, 8 \mathrm{H} ; \mathrm{CH}_{2} \mathrm{CH}_{3}\right), 1.38$ $\left(\mathrm{t}, J=7.1 \mathrm{~Hz}, 12 \mathrm{H} ; \mathrm{CH}_{2} \mathrm{CH}_{3}\right)$ ppm. ${ }^{13} \mathrm{C}\left\{{ }^{1} \mathrm{H}\right\}$ NMR $(125 \mathrm{MHz}$, $\left.\mathrm{CDCl}_{3}\right): \delta=158.6,144.5,144.4,135.9,125.6,125.3,119.8,117.1$ 108.9, 47.2, 12.4 ppm. HRMS (ESI/Orbitrap) $m / z:[\mathrm{M}+\mathrm{H}]^{+}$calcd for $\mathrm{C}_{24} \mathrm{~N}_{4} \mathrm{H}_{29}, 373.2387$; found, 373.2385 .

Synthesis of 9-Oxo-9,12-dihydroquinolino[7,8- $h$ ]quinoline4-sulfonic Acid (27). Sodium sulfite $(0.084 \mathrm{~g}, 6.667 \mathrm{mmol})$ and 16 $(0.050 \mathrm{~g}, 0.167 \mathrm{mmol})$ in water $(10 \mathrm{~mL})$ was refluxed for $4 \mathrm{~h}$. The solvent was removed, and the crude reaction mixture was dissolved in DMSO and filtered then precipitated with EtOAc to give 27 (0.093 g, 26\%). ${ }^{1} \mathrm{H}$ NMR ( $500 \mathrm{MHz}$, DMSO- $\left.d_{6}\right): \delta=15.47(\mathrm{~d}, J=4.2 \mathrm{~Hz}, 1 \mathrm{H}$; $\mathrm{NH}), 9.20(\mathrm{~d}, J=4.6 \mathrm{~Hz}, 1 \mathrm{H}), 9.03(\mathrm{~d}, J=9.2 \mathrm{~Hz}, 1 \mathrm{H}), 8.45(\mathrm{~d}, J=8.5$ $\mathrm{Hz}, 1 \mathrm{H}), 8.30(\mathrm{dd}, J=6.7,6.7 \mathrm{~Hz}, 1 \mathrm{H}), 8.16(\mathrm{~d}, J=9.2 \mathrm{~Hz}, 1 \mathrm{H}), 8.13$ $(\mathrm{d}, J=4.6 \mathrm{~Hz}, 1 \mathrm{H}), 7.94(\mathrm{~d}, J=8.6 \mathrm{~Hz}, 1 \mathrm{H}), 6.34(\mathrm{~d}, J=7.1 \mathrm{~Hz}, 1 \mathrm{H})$ ${ }^{13} \mathrm{C}\left\{{ }^{1} \mathrm{H}\right\}$ NMR $\left(125 \mathrm{MHz}\right.$, DMSO- $\left.d_{6}\right): \delta=176.5,152.9,148.2,147.2$, 139.6, 139.6, 135.8, 127.9, 127.4, 125.2, 124.4, 123.2, 123.1, 118.9, $116.7,110.6 \mathrm{ppm}$. HRMS (ESI/TOF) $\mathrm{m} / z$ : $[\mathrm{M}-\mathrm{H}]^{-}$calcd for $\mathrm{C}_{16} \mathrm{H}_{9} \mathrm{~N}_{2} \mathrm{O}_{4} \mathrm{~S}$, 325.0283; found, 325.0289.

Synthesis of 9-(Pyridin-4-yl)quinolino[7,8-h]quinoline4(1H)-one (28). A 1,4-dioxane/water solution $(3: 2,20 \mathrm{~mL})$ was added to a mixture of $17(100 \mathrm{mg}, 0.258 \mathrm{mmol})$, 4-pyridine boronic acid pinacol ester $(211 \mathrm{mg}, 1.03 \mathrm{mmol})$, caesium carbonate $(420 \mathrm{mg}$, $1.29 \mathrm{mmol})$, and the $\mathrm{Pd}\left(\mathrm{PPh}_{3}\right)_{4}$ catalyst $(15 \mathrm{mg}, 0.013 \mathrm{mmol})$ and stirred at $80{ }^{\circ} \mathrm{C}$ for $16 \mathrm{~h}$ under an atmosphere of Ar. Water $(50 \mathrm{~mL})$ was added, and the residue was extracted with $\mathrm{CHCl}_{3}$. The aqueous layer was washed with $\mathrm{CHCl}_{3}(2 \times 25 \mathrm{~mL})$, and the combined organic layers were dried with $\mathrm{MgSO}_{4}$, filtered, and dried in vacuo to give 28 ( $80 \mathrm{mg}, 96 \%$ ). Purification by column chromatography was achieved by passing the crude compound through activated alumina (neutral) with $2 \% \mathrm{MeOH}$ in DCM (with a few drops of $\left.\mathrm{Et}_{3} \mathrm{~N}\right) .{ }^{1} \mathrm{H}$ NMR $(700$ MHz, DMSO- $\left.d_{6}\right): \delta=15.46(\mathrm{~d}, J=5.1 \mathrm{~Hz}, 1 \mathrm{H} ; \mathrm{NH}), 9.29(\mathrm{~d}, J=4.6$ $\mathrm{Hz}, 1 \mathrm{H}), 8.84(\mathrm{dd}, J=1.4,4.6 \mathrm{~Hz}, 2 \mathrm{H}), 8.50(\mathrm{~d}, J=8.5 \mathrm{~Hz}, 1 \mathrm{H}), 8.33-$ $8.31(\mathrm{~m}, 1 \mathrm{H}), 8.18(\mathrm{~d}, J=9.0 \mathrm{~Hz}, 1 \mathrm{H}), 7.98-7.95(\mathrm{~m}, 2 \mathrm{H}), 7.87(\mathrm{~d}, J$ $=4.6 \mathrm{~Hz}, 1 \mathrm{H}), 7.68(\mathrm{dd}, J=1.4,4.6 \mathrm{~Hz}, 2 \mathrm{H}), 6.36(\mathrm{dd}, J=1.4,7.4 \mathrm{~Hz}$, 1H) ppm. ${ }^{13} \mathrm{C}\left\{{ }^{1} \mathrm{H}\right\}$ NMR $\left(176 \mathrm{MHz}, \mathrm{CDCl}_{3}\right): \delta=150.5,148.4,147.5$, $146.9,145.2,140.3,140.2,140.1,136.6,129.9,126.1,125.5,125.2$, 125.0, 124.8, 123.7, 122.4, 117.5, 111.5 ppm. HRMS (ESI/Orbitrap) $m / z:[\mathrm{M}+\mathrm{H}]^{+}$calcd for $\mathrm{C}_{21} \mathrm{H}_{14} \mathrm{~N}_{3} \mathrm{O}$, 324.1131; found, 324.1131. $\mathrm{C}_{21} \mathrm{H}_{13} \mathrm{~N}_{3} \mathrm{O} \cdot 1.5 \mathrm{H}_{2} \mathrm{O}$ : calcd C, 71.92; H, 4.61; N, 11.99; found $\mathrm{C}$, 72.23; H, 4.33; N, 12.03. IR (KBr disk): $\tilde{\nu}=3433,1627,1614,1571$, $1525,1504,1188,831 \mathrm{~cm}^{-1}$.

Synthesis of 4,9-Di(pyridin-4-yl)quinolino[7,8-h]quinoline (29). Dry DMF $(20 \mathrm{~mL})$ was added to a mixture of $17(100 \mathrm{mg}$, $0.258 \mathrm{mmol})$, 4-pyridine pinacol ester $(211 \mathrm{mg}, 1.03 \mathrm{mmol})$, caesium carbonate $(420 \mathrm{mg}, 1.29 \mathrm{mmol})$, and the $\mathrm{Pd}\left(\mathrm{PPh}_{3}\right)_{4}$ catalyst $(30 \mathrm{mg}$, $0.026 \mathrm{mmol})$ and stirred at $80{ }^{\circ} \mathrm{C}$ for $21 \mathrm{~h}$. Water $(50 \mathrm{~mL})$ was added, and the residue was extracted with $\mathrm{CHCl}_{3}$. The organic layer was washed with water $(3 \times 50 \mathrm{~mL})$, dried with $\mathrm{MgSO}_{4}$, filtered, and dried in vacuo. The product was purified by recrystallization from hot $\mathrm{CH}_{2} \mathrm{Cl}_{2}$ to give $29(26 \mathrm{mg}, 26 \%)$. Crystals suitable for X-ray crystallography were grown by the slow evaporation of 29 in a 1:1:1 $\mathrm{DCM} / \mathrm{MeOH} / \mathrm{CHCl}_{3}$ solvent mixture. ${ }^{1} \mathrm{H}$ NMR $\left(700 \mathrm{MHz}, \mathrm{CDCl}_{3}\right)$ $\delta=9.46(\mathrm{~d}, J=4.2 \mathrm{~Hz}, 2 \mathrm{H} ; 2,11-\mathrm{H}), 8.84(\mathrm{dd}, J=1.6,4.3 \mathrm{~Hz}, 4 \mathrm{H} ; 2-$ Py- $H$ ), 7.99 (d, $J=8.8 \mathrm{~Hz}, 2 \mathrm{H} ; 5,8-H), 7.94$ (d, $J=8.8 \mathrm{~Hz}, 2 \mathrm{H} ; 6,7-H)$, 7.54 (d, $J=4.3 \mathrm{~Hz}, 2 \mathrm{H} ; 3,10-H), 7.51(\mathrm{dd}, J=1.6,4.3 \mathrm{~Hz}, 4 \mathrm{H} ; 3-\mathrm{Py}-\mathrm{H})$ ppm. ${ }^{13} \mathrm{C}\left\{{ }^{1} \mathrm{H}\right\}$ NMR $\left(176 \mathrm{MHz}, \mathrm{CDCl}_{3}\right): \delta=150.2$ (C2-Py, C2'-Py), 149.8 (C2, C11), 147.9 (C12a, C12c), 146.5 (C4, C9), 145.6 (C4-Py, C4'-Py), 135.5 (C4a, C8a), 128.1 (C6, C7), 126.9 (C12b), 125.7 (C5, C8), 125.6 (C6a), 124.6 (C3-Py, C3'-Py), 121.0 (C3, C10) ppm. HRMS (ESI/Orbitrap) $m / z:[\mathrm{M}+\mathrm{H}]^{+}$calcd for $\mathrm{C}_{26} \mathrm{H}_{17} \mathrm{~N}_{4}, 385.1448$; found, 385.1447. $\mathrm{C}_{26} \mathrm{H}_{16} \mathrm{~N}_{4} \cdot 0.8 \mathrm{CH}_{2} \mathrm{Cl}_{2}$ : calcd C, 71.35; H, 3.93; N, 12.43; found $\mathrm{C}, 71.35 ; \mathrm{H}, 3.79 ; \mathrm{N}, 12.76$. UV-vis $\left(\mathrm{CHCl}_{3}\right) \lambda_{\max }(\varepsilon / \mathrm{L}$ $\left.\mathrm{mol}^{-1} \mathrm{~cm}^{-1}\right): 278(58,200), 359(5820), 377(6970) \mathrm{nm}$. IR (FT): $\tilde{\nu}=$ $3033,1596,1580,1413,1067,871,830,775,704 \mathrm{~cm}^{-1}$.

Synthesis of 4,9-Di(pyridin-3-yl)quinolino[7,8-h]quinoline (30). Dry DMF $(25 \mathrm{~mL})$ was added to a mixture of $17(100 \mathrm{mg}$,
$0.258 \mathrm{mmol}), 3$-pyridine boronic acid pinacol ester $(211 \mathrm{mg}, 1.03$ $\mathrm{mmol})$, caesium carbonate $(420 \mathrm{mg}, 1.29 \mathrm{mmol}),(t-\mathrm{Bu})_{3} \mathrm{PHBF}_{4}(8$ $\mathrm{mg}, 0.026 \mathrm{mmol})$, and $\mathrm{Pd}_{2}(\mathrm{dba})_{3}(24 \mathrm{mg}, 0.026 \mathrm{mmol})$. The suspension was stirred at $100{ }^{\circ} \mathrm{C}$ for $20 \mathrm{~h}$ under an atmosphere of Ar. Water $(50 \mathrm{~mL})$ was added, and the reaction mixture was basified with $6 \mathrm{M} \mathrm{KOH}(40 \mathrm{~mL})$ and extracted with $\mathrm{CHCl}_{3}$. The organic layer was washed with water $(3 \times 50 \mathrm{~mL})$, dried with $\mathrm{MgSO}_{4}$, filtered, and dried in vacuo. The product was purified by recrystallization from hot DCE to give $30(30 \mathrm{mg}, 30 \%) .{ }^{1} \mathrm{H}$ NMR (500 MHz, DMSO- $\left.d_{6}\right): \delta=$ $9.63(\mathrm{~d}, J=5.0 \mathrm{~Hz}, 2 \mathrm{H} ; 2,11-\mathrm{H}), 8.95$ (br s, $2 \mathrm{H} ; 2-\mathrm{Py}-\mathrm{H}), 8.90$ (d, $J=$ $4.0 \mathrm{~Hz}, 2 \mathrm{H}$; 6-Py-H), 8.52 (d, J = 9.0 Hz, 2H; 5,8-H), 8.32 (d, $J=9.0$ $\mathrm{Hz}, 2 \mathrm{H} ; 6,7-H), 8.29(\mathrm{~d}, J=5.0 \mathrm{~Hz}, 2 \mathrm{H} ; 3,10-H), 8.23(\mathrm{~d}, J=7.6 \mathrm{~Hz}$, $2 \mathrm{H}$; 4-Py-H), 7.79-7.76 (m, 2H; 5-Py-H) ppm. ${ }^{13} \mathrm{C}\left\{{ }^{1} \mathrm{H}\right\}$ NMR $(125$ MHz, DMSO- $d_{6}$ ): $\delta=150.9$ (C6-Py, C6'-Py), 150.2 (C2-Py, C2'-Py), 147.8 (C2, C11), 144.1 (C12a, C12c), 138.1 (C4-Py, C4'-Py), 136.5 (C3-Py, C3'-Py), 136.3 (C4, C9), 134.0 (C4a, C8a), 133.0 (C6a), 129.8 (C5, C8), 127.3 (C6, C7), 126.4 (C12b), 124.4 (C5-Py, C5'Py), 124.0 (C3, C10) ppm. HRMS (ESI/TOF) $m / z:[\mathrm{M}+\mathrm{H}]^{+}$calcd for $\mathrm{C}_{26} \mathrm{H}_{17} \mathrm{~N}_{4}, 385.1448$; found, 385.1482 .

Synthesis of 4-Bromo-9-(pyridin-4-yl)quinolino[7,8-h]quinoline (31). Phosphorous oxybromide $(266 \mathrm{mg}, 0.928 \mathrm{mmol})$ was added to 28 ( $100 \mathrm{mg}, 0.309 \mathrm{mmol})$ and stirred at $200{ }^{\circ} \mathrm{C}$ for 30 min under at atmosphere of $\mathrm{Ar}$. $\mathrm{A} \mathrm{MeOH} / \mathrm{CH}_{2} \mathrm{Cl}_{2}$ solution (1:10, 33 $\mathrm{mL}$ ) was added, the reaction mixture sonicated, and then it was basified with $6 \mathrm{M} \mathrm{KOH}(10 \mathrm{~mL})$. Water $(50 \mathrm{~mL})$ was added to the reaction mixture, and the organic layer was collected. The aqueous layer was washed with $\mathrm{MeOH} / \mathrm{CH}_{2} \mathrm{Cl}_{2}(1: 10,66 \mathrm{~mL})$, and the combined organic layers were dried with $\mathrm{MgSO}_{4}$, filtered, and dried in vacuo to give $31(65 \mathrm{mg}, 54 \%) .{ }^{1} \mathrm{H}$ NMR $\left(700 \mathrm{MHz}, \mathrm{DMSO}-d_{6}\right): \delta=$ $19.78(\mathrm{~s}, 1 \mathrm{H} ; \mathrm{NH}), 9.67(\mathrm{~d}, J=4.3 \mathrm{~Hz}, 1 \mathrm{H}), 9.33(\mathrm{~d}, J=5.2 \mathrm{~Hz} 1 \mathrm{H})$, $8.97(\mathrm{~s}, 2 \mathrm{H}), 8.72-8.70(\mathrm{~m} \mathrm{lH}), 8.66-8.65(\mathrm{~m}, 1 \mathrm{H}), 8.62(\mathrm{~d}, J=5.2$ $\mathrm{Hz}, 1 \mathrm{H}) 8.59(\mathrm{dd}, J=1.2,9.0 \mathrm{~Hz}, 1 \mathrm{H}), 8.33(\mathrm{~d}, J=5.2 \mathrm{~Hz}, 1 \mathrm{H}), 8.33-$ $8.31(\mathrm{~m}, 1 \mathrm{H}), 7.83(\mathrm{~s}, 2 \mathrm{H}) \mathrm{ppm} .{ }^{13} \mathrm{C}\left\{{ }^{1} \mathrm{H}\right\}$ NMR $(176 \mathrm{MHz}$, DMSO$\left.d_{6}\right): \delta=152.1,149.6,147.9,146.1,143.6,141.0,139.0,137.0,130.7$, $130.5,129.2,128.9,127.8,127.4,127.3,126.0,124.7,123.8,116.2$. HRMS (ESI/Orbitrap) $m / z:[\mathrm{M}+\mathrm{H}]^{+}$calcd for $\mathrm{C}_{21} \mathrm{H}_{13}{ }^{79} \mathrm{BrN}_{3}$, 386.0287; found, 386.0280 .

Experimental Determination of $\mathrm{p} K_{\mathrm{aH}}$ Values. A PerkinElmer Lambda 40 or Agilent Cary 60 UV-vis spectrophotometer connected with optical fibre cables to an external cell compartment inside a MBraun Unilab glovebox filled with argon (5.0 purity) was used for all UV-vis spectrophotometric titrations. This setup ensured that moisture and oxygen contents during titrations were always under $10 \mathrm{ppm}$.

Triflic acid (Aldrich, 99+\%) and tert-butylimino-tris(pyrrolidino)phosphorane (Fluka, $\geq 97 \%$ ) were used to prepare acidic and basic titrant solutions. The concentrations of the titrant solutions were in the range of $1-5 \times 10^{-3} \mathrm{~mol} \mathrm{~L}^{-1}$, and the concentrations of the quinolinoquinoline derivatives and reference compounds were in the range of $1-14 \times 10^{-5} \mathrm{~mol} \mathrm{~L}^{-1}$. Acetonitrile (Romil $190 \mathrm{SpS}$ far UV/ gradient quality) was used as the solvent after drying with molecular sieves ( $3 \AA$ ) for at least $12 \mathrm{~h}$, which lowered the water content to a range of $2-6 \mathrm{ppm}$.

The determination of $\mathrm{p} K_{\mathrm{aH}}$ values was based on the measurement of differences in the basicities of two bases. The first one was a quinolinoquinoline derivative, and the second one is a reference base with a previously known $\mathrm{p} K_{\mathrm{aH}}$ value. ${ }^{62}$ Both compound solutions were titrated individually and as a mixture in order to obtain the spectra of neutral and fully protonated as well as some partially protonated forms. The spectrophotometric data was used to calculate the dissociation levels (see eq 1) of conjugate acids of both bases in all mixtures formed during the titration. Using the dissociation levels $(\alpha)$, the differences in $\mathrm{p} K_{\mathrm{aH}}$ values $\left(\Delta \mathrm{p} K_{\mathrm{aH}}\right)$ of the quinolinoquinoline and the reference base can be calculated according to eq 2 .

$$
\begin{aligned}
& \alpha=\frac{[\mathrm{B}]}{[\mathrm{B}]+\left[\mathrm{BH}^{+}\right]} \\
& \Delta \mathrm{p} K_{\mathrm{aH}}=\log \frac{\alpha_{1}\left(1-\alpha_{2}\right)}{\alpha_{2}\left(1-\alpha_{1}\right)}
\end{aligned}
$$


Bases with previously published $\mathrm{p} K_{\mathrm{aH}}$ values were used as reference bases. ${ }^{62}$ All studied quinolinoquinolines were measured against at least two reference bases.

Two of the bases were converted to triflate salts and additionally purified for $\mathrm{p} K_{\mathrm{aH}}$ measurements:

Compound 17 was suspended in $\mathrm{MeCN}$ and $\mathrm{TfOH}$ in $\mathrm{MeCN}$ was added dropwise until the color of the solution did not change the color anymore. The salt dissolved in $\mathrm{MeCN}$ completely. $\mathrm{MeCN}$ was then evaporated, and compound $\mathbf{1 7}$ was recrystallized from $\mathrm{MeOH}$ to get light brown needle-shaped crystals $17 \mathrm{H}^{+} \mathrm{TfO}^{-}$.

Compound 26 was dissolved in $\mathrm{MeCN}$ and $\mathrm{TfOH}$ in $\mathrm{MeCN}$ was added dropwise until the dark color became light brown, and the solution did not change the color anymore. The solvent and excess of $\mathrm{TfOH}$ were evaporated to dryness, and the oily substance obtained was washed with $\mathrm{Et}_{2} \mathrm{O}$ (dark oil was extracted). The portion of the compound (few crystals) suitable for $\mathrm{p} K_{\mathrm{aH}}$ determination was crystallized out from $\mathrm{CH}_{2} \mathrm{Cl}_{2}$ at $-15{ }^{\circ} \mathrm{C}$. Most of the compound was recrystallized from the mixture of $\mathrm{MeOH} /$ water (4:1) to obtain a yellow solid of $26 \mathrm{H}^{+} \mathrm{TfO}^{-}$.

Computational Details. Gas-phase PAs and GBs were calculated as protonation enthalpies and free energies, respectively, employing density functional theory calculations at the B3LYP/6-311++G$(3 \mathrm{df}, 2 \mathrm{p}) / / \mathrm{B} 3 \mathrm{LYP} / 6-31+\mathrm{G}(\mathrm{d}, \mathrm{p})$ level and using the following reaction

$$
\mathrm{B}_{(\mathrm{g})}+\mathrm{H}^{+}{ }_{(\mathrm{g})} \rightarrow \mathrm{BH}^{+}{ }_{(\mathrm{g})}
$$

where $\mathrm{B}$ and $\mathrm{BH}^{+}$denote a base in question and its conjugate acid, respectively. Frequency analysis was used to calculate thermal corrections and validate the nature of the optimized stationary points. In this way, all thermodynamic values reported here correspond to a room temperature of $298.15 \mathrm{~K}$ and a normal pressure of $1 \mathrm{~atm}$. The choice of this methodology was prompted by its demonstrated accuracy in modeling acid/base features of various organic and inorganic systems. ${ }^{7,13,83}$

Implicit isodensity polarizable continuum model (IPCM) by Tomasi and co-workers ${ }^{67}$ was used to account for the effect of the acetonitrile solution, and the corresponding $\mathrm{p} K_{\mathrm{aH}}$ values were calculated using the empirical correlation

$$
\mathrm{p} K_{\mathrm{aH}}(\mathrm{MeCN})=0.5751 \cdot \mathrm{PA}(\mathrm{MeCN})-144.1 \text { units }
$$

derived by Despotovic and co-workers ${ }^{68}$ in the case of 10 pyridinebased organic bases and employing the recommended (IPCM)/ B3LYP/6-311+G(d,p)//B3LYP/6-31G(d) model. In systems 15 and 20, where the prototropic tautomerism in neutral bases causes a proton transfer from the $-\mathrm{OH}$ substituent to the pyridine nitrogen, and where the protonation formally occurs on the thus-derived carbonyl oxygen atom, the $\mathrm{p} K_{\mathrm{aH}}$ values were calculated through the proton transfer reaction: $\mathrm{B}-\mathrm{H}^{+}+\mathrm{B}_{\mathrm{REF}} \rightarrow \mathrm{B}+\mathrm{B}_{\mathrm{REF}}-\mathrm{H}^{+}$, employing Schwesinger's vinamidine superbases as a reference base $B_{\mathrm{REF}}\left(\mathrm{pK}_{\mathrm{aH}, \mathrm{EXP}}=29.2\right) .{ }^{69}$ All calculations were performed using Gaussian09 software. ${ }^{70}$

\section{ASSOCIATED CONTENT}

\section{(s) Supporting Information}

The Supporting Information is available free of charge at https://pubs.acs.org/doi/10.1021/acs.joc.0c01428.

Synthesis of compounds 14 and 16; ${ }^{1} \mathrm{H}$ NMR and ${ }^{13} \mathrm{C}$ NMR spectra for compounds 17-19, 26-31; general procedures and crystal data for X-ray crystallographic analysis of compounds 28, 29, and 33; reference and $\Delta \mathrm{p} K_{\mathrm{aH}}$ values for the determination of the experimental $\mathrm{p} K_{\mathrm{aH}}$ values for compounds 2, 13, 15-17, 20, and 26; and Cartesian coordinates for all computed structures together with their total electronic energies obtained at the B3LYP/6-31+G(d,p) level of theory (PDF)

Crystallographic data for compounds 28, 29. and 33 (CIF)

\section{AUTHOR INFORMATION}

\section{Corresponding Author}

Paul G. Plieger - School of Fundamental Sciences, Massey

University, Palmerston North 4442, New Zealand; ○ orcid.org/0000-0003-4886-7677; Email: p.g.plieger@ massey.ac.nz

\section{Authors}

Gareth J. Rowlands - School of Fundamental Sciences, Massey University, Palmerston North 4442, New Zealand; (1) orcid.org/0000-0002-8661-5860

Rebecca J. Severinsen - School of Fundamental Sciences, Massey University, Palmerston North 4442, New Zealand

Jenna K. Buchanan - School of Fundamental Sciences, Massey University, Palmerston North 4442, New Zealand

Karl J. Shaffer - School of Fundamental Sciences, Massey University, Palmerston North 4442, New Zealand

Heather T. Jameson - School of Fundamental Sciences, Massey University, Palmerston North 4442, New Zealand

Nishani Thennakoon - School of Fundamental Sciences, Massey University, Palmerston North 4442, New Zealand

Ivo Leito - Institute of Chemistry, University of Tartu, Tartu 50411, Estonia; 이이.org/0000-0002-3000-4964

Märt Lõkov - Institute of Chemistry, University of Tartu, Tartu 50411, Estonia

Agnes Kütt - Institute of Chemistry, University of Tartu, Tartu 50411, Estonia; 이이이.org/0000-0002-1869-0383

Robert Vianello - Ruder Boškovíc Institute, Zagreb 10000, Croatia; (1) orcid.org/0000-0003-1779-4524

Ines Despotović - Ruder Boškovic Institute, Zagreb 10000, Croatia

Nena Radić - Ruder Boškovíc Institute, Zagreb 10000, Croatia; (1) orcid.org/0000-0001-7076-4020

Complete contact information is available at:

https://pubs.acs.org/10.1021/acs.joc.0c01428

\section{Notes}

The authors declare no competing financial interest.

\section{ACKNOWLEDGMENTS}

The work at Tartu was supported by the Estonian Research Council grant PRG690 and by EU through the European Regional Development Fund under project TK141 “Advanced materials and high-technology devices for energy recuperation systems" (2014-2020.4.01.15-0011). The work at Zagreb was supported by the Croatian Science Foundation under grant number IP-2014-09-3386. R.V., I.D., and N.R. wish to thank the Zagreb University Computing Centre (SRCE) for granting computational resources on the ISABELLA cluster. P.G.P. is grateful to Massey University for the award of a doctoral scholarship to R.J.S. We would also like to acknowledge Prof. William Henderson from Waikato University for performing high-resolution mass spectrometric analysis.

\section{REFERENCES}

(1) Alder, R. W.; Bowman, P. S.; Steele, W. R. S.; Winterman, D. R. The remarkable basicity of 1,8-bis(dimethylamino)naphthalene. Chem. Commun. 1968, 723-724.

(2) Ishikawa, T. Superbases for Organic Synthesis: Guanidines, Amidines, Phosphazenes and Related Organocatalysts; John Wiley \& Sons, 2009. 
(3) Pozharskii, A. F.; Ozeryanskii, V. A.; Filatova, E. A. Heterocyclic superbases: retrospective and current trends. Chem. Heterocycl. Compd. 2012, 48, 200-219.

(4) Ishikawa, T.; Harwood, L. Organic Superbases: The Concept at a Glance. Synlett 2013, 24, 2507-2509.

(5) Kaljurand, I.; Saame, J.; Rodima, T.; Koppel, I.; Koppel, I. A.; Kögel, J. F.; Sundermeyer, J.; Köhn, U.; Coles, M. P.; Leito, I. Experimental Basicities of Phosphazene, Guanidinophosphazene, and Proton Sponge Superbases in the Gas Phase and Solution. J. Phys. Chem. A 2016, 120, 2591-2604.

(6) Singh, A.; Ojha, A. K.; Jang, H. M. Strategic Design and Utilization of Molecular Flexibility for Straddling the Application of Organic Superbases: A DFT Study. ChemistrySelect 2018, 3, 837-842.

(7) Tandarić, T.; Vianello, R. Design of Exceptionally Strong Organic Superbases Based on Aromatic Pnictogen Oxides: Computational DFT Analysis of the Oxygen Basicity in the Gas Phase and Acetonitrile Solution. J. Phys. Chem. A 2018, 122, 1464-1471.

(8) Gerlt, J. A.; Kreevoy, M. M.; Cleland, W. W.; Frey, P. A. Understanding enzymic catalysis: the importance of short, strong hydrogen bonds. Chem. Biol. 1997, 4, 259-267.

(9) Pietrzak, M.; Wehling, J. P.; Kong, S.; Tolstoy, P. M.; Shenderovich, I. G.; López, C.; Claramunt, R. M.; Elguero, J.; Denisov, G. S.; Limbach, H.-H. Symmetrization of Cationic Hydrogen Bridges of Protonated Sponges Induced by Solvent and Counteranion Interactions as Revealed by NMR Spectroscopy. Chem.-Eur. J. 2010, $16,1679-1690$

(10) Scerba, M. T.; Leavitt, C. M.; Diener, M. E.; DeBlase, A. F.; Guasco, T. L.; Siegler, M. A.; Bair, N.; Johnson, M. A.; Lectka, T. $\mathrm{NH}^{+}-\mathrm{F}$ Hydrogen Bonding in a Fluorinated "Proton Sponge" Derivative: Integration of Solution, Solid-State, Gas-Phase, and Computational Studies. J. Org. Chem. 2011, 76, 7975-7984.

(11) Ozeryanskii, V. A.; Pozharskii, A. F. Simple and hydrolytically stable proton sponge based organic cation displaying hydrogen bonding and a number of related phenomena. Tetrahedron 2013, 69, $2107-2112$

(12) Sobczyk, L.; Grabowski, S. J.; Krygowski, T. M. Interrelation between H-Bond and Pi-Electron Delocalization. Chem. Rev. 2005, 105, 3513-3560.

(13) Maksić, Z. B.; Kovačević, B.; Vianello, R. Advances in Determining the Absolute Proton Affinities of Neutral Organic Molecules in the Gas Phase and Their Interpretation: A Theoretical Account. Chem. Rev. 2012, 112, 5240-5270.

(14) Wild, U.; Hübner, O.; Maronna, A.; Enders, M.; Kaifer, E.; Wadepohl, H.; Himmel, H.-J. The First Metal Complexes of the Proton Sponge 1,8-Bis (N,N, $\mathrm{N}^{\prime}, \mathrm{N}^{\prime}$-tetramethylguanidino)naphthalene: Syntheses and Properties. Eur. J. Inorg. Chem. 2008, 4440-4447.

(15) Wüstefeld, H.-U.; Kaska, W. C.; Schüth, F.; Stucky, G. D.; Bu, X.; Krebs, B. Transition Metal Complexes with the Proton Sponge 4,9Dichloroquino[7,8-h]quinoline: Highly Twisted Aromatic Systems and an Extreme "Out-of-Plane" Position of the Coordinated Transition Metal Atom. Angew. Chem., Int. Ed. 2001, 40, 3182-3184.

(16) Shaffer, K. J.; McLean, T. M.; Waterland, M. R.; Wenzel, M.; Plieger, P. G. Structural characterization of difluoro-boron chelates of quino[7,8-h] quinoline. Inorg. Chim. Acta 2012, 380, 278-283.

(17) Shaffer, K. J.; Wenzel, M.; Plieger, P. G. The first structurally characterised copper(II) complexes of quino[7,8-h]quinoline ligands. Polyhedron 2013, 52, 1399-1402.

(18) Gamage, S. N.; Morris, R. H.; Rettig, S. J.; Thackray, D. C.; Thorburn, I. S.; James, B. R. Formation of a trimethyldihydroperimidinium cation from proton sponge $[1,8$-bis(dimethylamino)naphthalene] during base-promoted reactions of rhodium and ruthenium complexes. J. Chem. Soc., Chem. Commun. 1987, 894-895.

(19) Yamasaki, T.; Nobutaka, O.; Yasunari, S.; Kozo, O.; Kenji, G.; Fumiko, N.; Masato, H.; Seichi, O. First Transition Metal Complex of 1,8-Bis(dimethylamino)naphthalene (proton sponge). Chem. Lett. 2004, 33, 928-929.
(20) Bencini, A.; Lippolis, V. 1,10-Phenanthroline: A versatile building block for the construction of ligands for various purposes. Coord. Chem. Rev. 2010, 254, 2096-2180.

(21) Alreja, P.; Kaur, N. Recent advances in 1,10-phenanthroline ligands for chemosensing of cations and anions. RSC Adv. 2016, 6, 23169-23217.

(22) Note, the chemical structure substructure search was performed on 17 th October 2019

(23) Pozharskii, A. F.; Ozeryanskii, V. A.; Mikshiev, V. Y.; Chernyshev, A. V.; Metelitsa, A. V.; Antonov, A. S. Proton-induced fluorescence in modified quino[7,8-h] quinolines: dual sensing for protons and $\pi$-donors. Org. Biomol. Chem. 2019, 17, 8221-8233.

(24) Shaffer, K. J.; Parr, D. C.; Wenzel, M.; Rowlands, G. J.; Plieger, P. G. The Proton Sponge Effect: Substitution of Quino[7,8h] quinoline and the First Structurally Characterised Derivatives. Eur. J. Org. Chem. 2012, 6967-6975.

(25) Zirnstein, M. A.; Staab, H. A. Quino[7,8-h]quinoline, a New Type of "Proton Sponge". Angew. Chem., Int. Ed. Engl. 1987, 26, 460461.

(26) Krieger, C.; Newsom, I.; Zirnstein, M. A.; Staab, H. A. Structures of Quino[7,8-h]quinoline and Quino[8,7-h]quinoline. Angew. Chem., Int. Ed. Engl. 1989, 28, 84-86.

(27) Buu-Hoï, N. P.; Dufour, M.; Jacquignon, P. Carcinogenic nitrogen compounds. Part LXI. The Skraup reaction with diamines derived from acenaphthene and anthracene. J. Chem. Soc. C 1968, 2070-2072.

(28) Hancock, R. D. The pyridyl group in ligand design for selective metal ion complexation and sensing. Chem. Soc. Rev. 2013, 42, 15001524.

(29) Bazargan, M.; Mirzaei, M.; Franconetti, A.; Frontera, A. On the preferences of five-membered chelate rings in coordination chemistry: insights from the Cambridge Structural Database and theoretical calculations. Dalton Trans. 2019, 48, 5476-5490.

(30) Carolan, A. N.; Cockrell, G. M.; Williams, N. J.; Zhang, G.; VanDerveer, D. G.; Lee, H.-S.; Thummel, R. P.; Hancock, R. D. Selectivity of the Highly Preorganized Tetradentate Ligand 2,9$\mathrm{Di}($ pyrid-2-yl)-1,10-phenanthroline for Metal Ions in Aqueous Solution, Including Lanthanide(III) Ions and the Uranyl(VI) Cation. Inorg. Chem. 2013, 52, 15-27.

(31) Shaffer, K. J.; Davidson, R. J.; Burrell, A. K.; McCleskey, T. M.; Plieger, P. G. Encapsulation of the $\mathrm{Be}^{\mathrm{II}}$ Cation: Spectroscopic and Computational Study. Inorg. Chem. 2013, 52, 3969-3975.

(32) Glover, J. E.; Martin, D. J.; Plieger, P. G.; Rowlands, G. J. Planar Chiral Triazole-Based Phosphanes Derived from [2.2]Paracyclophane and Their Activity in Suzuki Coupling Reactions. Eur. J. Org. Chem. 2013, 1671-1675.

(33) Jayasundera, K. P.; Engels, T. G. W.; Lun, D. J.; Mungalpara, M. N.; Plieger, P. G.; Rowlands, G. J. The synthesis of planar chiral pseudo-gem aminophosphine pre-ligands based on [2.2] paracyclophane. Org. Biomol. Chem. 2017, 15, 8975-8984.

(34) Plieger, P. G.; Parsons, S.; Parkin, A.; Tasker, P. A. Transport of metal salts; encapsulation of anions in dinuclear $\mathrm{Cu}$ (II) complexes $\left[\mathrm{Cu}_{2} \mathrm{~L}_{2} \mathrm{SO}_{4}\right] \mathrm{SO}_{4}$ and $\left[\mathrm{Cu}_{2} \mathrm{~L}_{2} \mathrm{BF}_{4}\right]\left(\mathrm{BF}_{4}\right)_{3}$, where $\mathrm{L}=2,2^{\prime}$ - $[1,6-$ hexanediylbis [(methylimino) methylene] ] bis [4-tert-butyl-6(phenylazomethinyl)phenol]. J. Chem. Soc., Dalton Trans. 2002, 3928-3930

(35) Wenzel, M.; Bruere, S. R.; Knapp, Q. W.; Tasker, P. A.; Plieger, P. G. Zwitterionic dicopper helicates: anion encapsulation and binding studies. Dalton Trans. 2010, 39, 2936-2941.

(36) Wenzel, M.; Knapp, Q. W.; Plieger, P. G. A bissalicylaldoximato-copper(II) receptor for selective sulfate uptake. Chem. Commun. 2011, 47, 499-501.

(37) Fulton, J. R.; Glover, J. E.; Kamara, L.; Rowlands, G. J. Facile synthesis of planar chiral $\mathrm{N}$-oxides and their use in Lewis base catalysis. Chem. Commun. 2011, 47, 433-435.

(38) Glover, J. E.; Plieger, P. G.; Rowlands, G. J. An Enantiomerically Pure Pyridine NC-Palladacycle Derived from [2.2]Paracyclophane. Aust. J. Chem. 2014, 67, 374-380. 
(39) Rowlands, G. J.; Hitchcock, P. B.; Hodgson, A. C. C. The first examples of planar chiral organic benzimidazole derivatives. Synlett 2006, 2625-2628.

(40) Edel, A.; Marnot, P. A.; Sauvage, J. P. Unexpected synthesis of 2methyl-1,3-diazapyrene from 1,8-diaminonaphthalene. Tetrahedron Lett. 1985, 26, 727-728.

(41) Honda, K.; Nakanishi, H.; Yabe, A. Reaction of 1,8Naphthalenediamine with Dimethyl and Diethyl Acetylenedicarboxylates. Bull. Chem. Soc. Jpn. 1983, 56, 2338-2340.

(42) Favre, H. A.; Powell, W. H. Nomenclature of Organic Chemistry: IUPAC Recommendations and Preferred Names 2013; Royal Society of Chemistry: Cambridge, U.K., 2013.

(43) Rasmussen, S. C. The nomenclature of fused-ring arenes and heterocycles: a guide to an increasingly important dialect of organic chemistry. Chem Texts 2016, 2, 16.

(44) Moss, G. P. Nomenclature of fused and bridged fused ring systems (IUPAC Recommendations 1998). Pure Appl. Chem. 1998, $70,143-216$.

(45) IUPAC. Definitive rules for nomenclature of organic chemistry. J. Am. Chem. Soc. 1960, 82, 5545-5574.

(46) Iwai, I.; Hara, S. Polarisation der heterozyklischen Ringe mit aromatischem Charakter. LXXXIV. J. Pharm. Soc. Jpn. 1950, 70, 394400.

(47) Ila, H.; Panda, K.; Siddiqui, I.; Mahata, P. K.; Junjappa, H. Heteroannulation of 3-Bis (methylthio)acrolein with Aromatic Amines - A Convenient Highly Regioselective Synthesis of 2-(Methylthio)quinolines and their Benzo/Hetero Fused Analogs - A Modified Skraup Quinoline Synthesis. Synlett 2004, 449-452.

(48) Zewge, D.; Chen, C.-y.; Deer, C.; Dormer, P. G.; Hughes, D. L. A Mild and Efficient Synthesis of 4-Quinolones and Quinolone Heterocycles. J. Org. Chem. 2007, 72, 4276-4279.

(49) Takei, H.; Miura, M.; Sugimura, H.; Okamura, H. Synthesis of alkyl- or aryl-substituted heterocycles: nickel complex catalyzed coupling reaction of heterocyclic sulfides and thiols with Grignard reagents. Chem. Lett. 1979, 1447-1450.

(50) Testaferri, L.; Tiecco, M.; Tingoli, M.; Bartoli, D.; Massoli, A. The reactions of some halogenated pyridines with methoxide and methanethiolate ions in dimethylformamide. Tetrahedron 1985, 41, 1373-1384.

(51) Angiolelli, M. E.; Casalnuovo, A. L.; Selby, T. P. Palladiumcatalyzed cross-coupling of benzylzinc reagents with methylthio $\mathrm{N}$ heterocycles: a new coupling reaction with unusual selectivity. Synlett 2000, 905-907.

(52) Shook, B. C.; Chakravarty, D.; Jackson, P. F. Microwave-assisted Sonogashira-type cross couplings of various heterocyclic methyl thioethers. Tetrahedron Lett. 2009, 50, 1013-1015.

(53) Melzig, L.; Metzger, A.; Knochel, P. Room temperature crosscoupling of highly functionalized organozinc reagents with thiomethylated N-heterocycles by nickel catalysis. J. Org. Chem. 2010, 75, 21312133.

(54) Koley, M.; Wimmer, L.; Schnürch, M.; Mihovilovic, M. D. $\mathrm{Pd}(0)$-catalyzed $\mathrm{Cu}(\mathrm{I})$-thiophene-2-carboxylate-mediated cross-coupling of heteroaromatic thioethers and boronic acids - First Liebeskind-Srogl reaction in water. J. Heterocycl. Chem. 2013, 50, 1368-1373.

(55) Yamamoto, K.; Otsuka, S.; Nogi, K.; Yorimitsu, H. NickelCatalyzed Cross-Coupling Reaction of Aryl Sulfoxides with Arylzinc Reagents: When the Leaving Group is an Oxidant. ACS Catal. 2017, 7, $7623-7628$.

(56) Pratap, R.; Yorimitsu, H. Palladium-Catalyzed Amination of Aryl Sulfides and Sulfoxides with Azaarylamines of Poor Nucleophilicity. Synthesis 2019, 51, 2705-2712.

(57) Strauss, C. R.; Trainor, R. W. Reactions of Ethyl Indole-2carboxylate in Aqueous Media at High Temperature. Aust. J. Chem. 1998, 51, 703-706.

(58) Schmittel, M.; Ammon, H. A Short Synthetic Route to 4,7Dihalogenated 1,10-Phenanthrolines with Additional Groups in 3,8Position: Soluble Precursors for Macrocyclic Oligophenanthrolines. Eur. J. Org. Chem. 1998, 785-792.
(59) Lennox, A. J. J.; Lloyd-Jones, G. C. Selection of boron reagents for Suzuki-Miyaura coupling. Chem. Soc. Rev. 2014, 43, 412-443.

(60) Kaljurand, I.; Kütt, A.; Sooväli, L.; Rodima, T.; Mäemets, V.; Leito, I.; Koppel, I. A. Extension of the self-consistent spectrophotometric basicity scale in acetonitrile to a full span of $28 \mathrm{pK}_{\mathrm{a}}$ units: unification of different basicity scales. J. Org. Chem. 2005, 70, 10191028.

(61) Lõkov, M.; Tshepelevitsh, S.; Heering, A.; Plieger, P. G.; Vianello, R.; Leito, I. On the Basicity of Conjugated Nitrogen Heterocycles in Different Media. Eur. J. Org. Chem. 2017, 4475-4489.

(62) Tshepelevitsh, S.; Kütt, A.; Lõkov, M.; Kaljurand, I.; Saame, J.; Heering, A.; Plieger, P. G.; Vianello, R.; Leito, I. On the Basicity of Organic Bases in Different Media. Eur. J. Org. Chem. 2019, 67356748.

(63) Raczyńska, E. D.; Gal, J.-F.; Maria, P.-C. Enhanced basicity of push-pull nitrogen bases in the gas phase. Chem. Rev. 2016, 116, 13454-13511.

(64) Coles, M. P.; Aragón-Sáez, P. J.; Oakley, S. H.; Hitchcock, P. B.; Davidson, M. G.; Maksíc, Z. B.; Vianello, R.; Leito, I.; Kaljurand, I.; Apperley, D. C. Superbasicity of a bis-guanidino compound with a flexible linker: a theoretical and experimental study. J. Am. Chem. Soc. 2009, 131, 16858-16868.

(65) Schwamm, R. J.; Vianello, R.; Maršavelski, A.; García, M. Á.; Claramunt, R. M.; Alkorta, I.; Saame, J.; Leito, I.; Fitchett, C. M.; Edwards, A. J.; Coles, M. P. ${ }^{15} \mathrm{~N}$ NMR spectroscopy, X-ray and neutron diffraction, quantum-chemical calculations, and UV/Visspectrophotometric titrations as complementary techniques for the analysis of pyridine-supported bicyclic guanidine superbases. J. Org. Chem. 2016, 81, 7612-7625.

(66) Vianello, R.; Maksić, Z. B. Interpretation of Brønsted Acidity by Triadic Paradigm: A G3 Study of Mineral Acids. J. Phys. Chem. A 2007, $111,11718-11724$.

(67) Miertuš, S.; Scrocco, E.; Tomasi, J. Electrostatic interaction of a solute with a continuum. A direct utilization of $\mathrm{AB}$ initio molecular potentials for the prevision of solvent effects. Chem. Phys. 1981, 55, $117-129$.

(68) Despotović, I.; Kovačević, B.; Maksić, Z. B. Pyridine and striazine as building blocks of nonionic organic superbases-a density functional theory B3LYP study. New J. Chem. 2007, 31, 447-457.

(69) Radić, N.; Maksić, Z. B. Basicity of neutral organic superbases with vinamidine structure in gas phase and acetonitrile: a density functional theory study. J. Phys. Org. Chem. 2012, 25, 1168-1176.

(70) Frisch, M. J.; Trucks, G. W.; Schlegel, H. B.; Scuseria, G. E.; Robb, M. A.; Cheeseman, J. R.; Scalmani, G.; Barone, V.; Mennucci, B.; Petersson, G. A.; Nakatsuji, H.; Caricato, M.; Li, X.; Hratchian, H. P.; Izmaylov, A. F.; Bloino, J.; Zheng, G.; Sonnenberg, J. L.; Hada, M.; Ehara, M.; Toyota, K.; Fukuda, R.; Hasegawa, J.; Ishida, M.; Nakajima, T.; Honda, Y.; Kitao, O.; Nakai, H.; Vreven, T.; Montgomery, J. A., Jr; Peralta, J. E.; Ogliaro, F.; Bearpark, M.; Heyd, J. J.; Brothers, E.; Kudin, K. N.; Taroverov, V. N.; Kobayashi, R.; Normand, J.; Raghavachari, K.; Rendell, A.; Burant, J. C.; Ivengar, S. S.; Tomasi, J.; Cossi, M.; Rega, N.; Millam, J. M.; Klene, M.; Knox, J. E.; Cross, J. B.; Bakken, V.; Adamo, C.; Jaramillo, J.; Gomperts, R.; Stratmann, R. E.; Yazyev, O.; Austin, A. J.; Cammi, R.; Pomelli, C.; Ochterski, J. W.; Martin, R. L.; Morokuma, K.; Zakrzewski, V. G.; Voth, G. A.; Salvador, P.; Dannenberg, J. J.; Dapprich, S.; Daniels, A. D.; Farkas, Ö.; Foresman, J. B.; Ortiz, J. V.; Cioslowski, J.; Fox, D. J. Gaussian 09, Revision D.01; Gaussian, Inc.: Wallingford CT, 2009. 